MORPHOLOGY OF THE MELON AND ITS TENDINOUS CONNECTIONS TO THE FACIAL MUSCLES IN BOTTLENOSE DOLPHINS (TURSIOPS TRUNCATUS)

\author{
Cally Harper
}

\author{
A Thesis Submitted to the \\ University of North Carolina Wilmington in Partial Fulfillment \\ Of the Requirements for the Degree of \\ Master of Science \\ Department of Biology and Marine Biology \\ University of North Carolina Wilmington \\ 2007
}

Approved by

Advisory Committee

Chair

Accepted by

Dean, Graduate School 
This thesis has been prepared in the style and format consistent with the journal Journal of Morphology 


\section{TABLE OF CONTENTS}

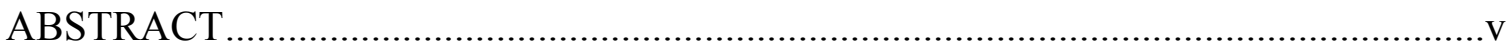

ACKNOWLEDGEMENTS .............................................................................. vii

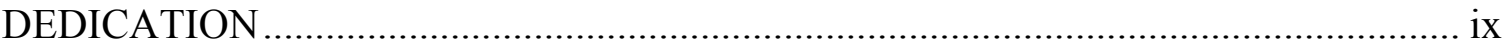

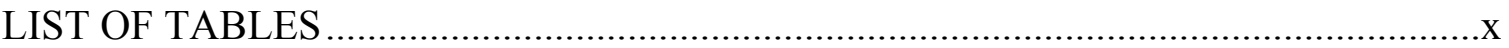

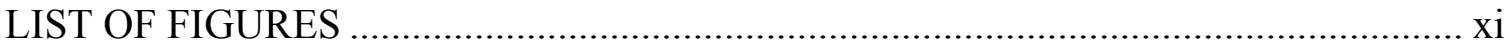

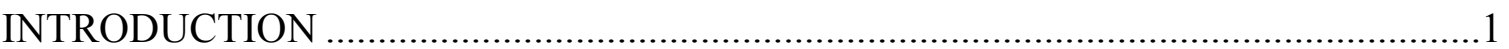

MATERIALS AND METHODS ......................................................................... 10

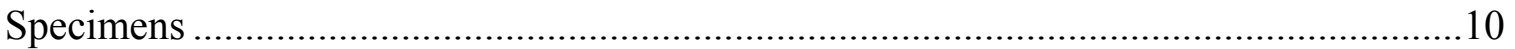

Gross Examination of the Bottlenose Dolphin Forehead ......................................... 10

Standard Gross Dissection Techniques......................................................... 10

Serial Sectioning Techniques................................................................... 12

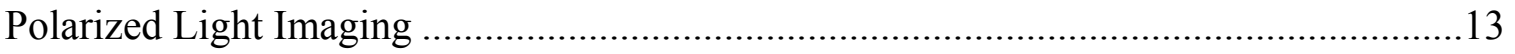

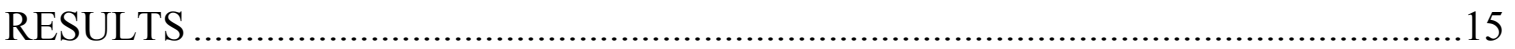

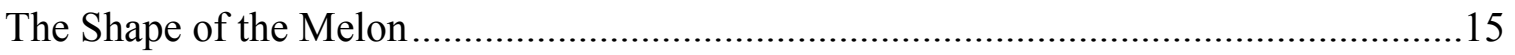

The Dermal Tissue Surrounding the Melon......................................................................24

Facial Muscles that Act Upon the Main Body of the Melon .........................................24

Facial Muscles that Act Upon the Cone of the Caudal Melon ........................................37

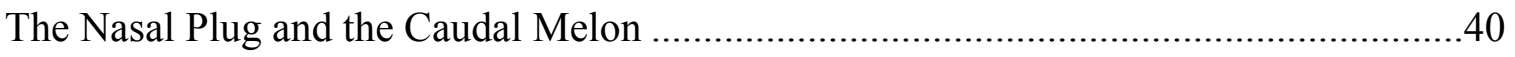

The Caudal Melon, the Nasal Plug, and the Nasal Plug Muscle ...................................43

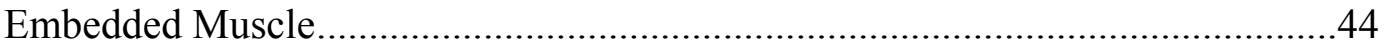

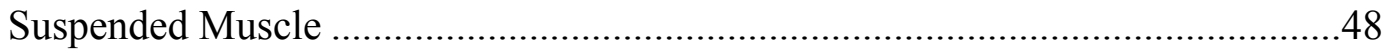

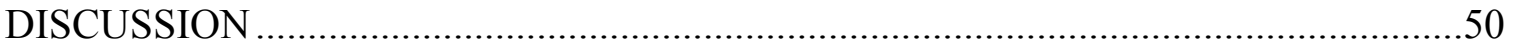


LITERATURE CITED . 


\begin{abstract}
The melon is a lipid rich structure located in the odontocete forehead that functions to propagate echolocation sounds into the surrounding aquatic environment. To date, the melon's abilities to guide and impedance match biosonar sounds to water has been attributed to its unique fatty acid composition. The melon, though, is also acted upon by facial muscles (rostral, pars anterointernus, and nasal plug muscles). The goals of this study were to investigate the gross morphology of the melon in the bottlenose dolphin (Tursiops truncatus) and to describe how it is tendinously connected to these facial muscles. Standard gross dissection $(n=8)$ and serial sectioning $(n=3)$ techniques were used to describe the melon and to identify the connections between it and the surrounding muscles and blubber in three orthogonal body planes. The melon was also thin-sectioned in three body planes $(n=3)$ and polarized light was used to reveal the birefringent collagen fibers within and surrounding the melon. This study identified two distinct regions of the melon, the main body and the caudal melon. The caudal melon is bilaterally asymmetrical. This study is the first to identify three regions of the right caudal melon, termed the cup, stem, and cone and two regions of the left caudal melon, named the cup and branch. All regions of the melon vary in shape and display locally specific muscle-tendon morphologies. The entire length of the melon, from the initial site of sound generation to its rostral end, is acted upon by facial muscles. These muscles have highly organized tendon populations that traverse the melon and insert into either the surrounding blubber, the connective tissue matrix of the nasal plug, or the connective tissue sheath surrounding the sound generators. The facial muscles and tendons also lie within multiple orthogonal planes, which suggest that the melon is capable of changing
\end{abstract}


its shape in multiple planes. Thus, the sound propagation pathway from the echolocation sound generators to the surrounding water appears to be a tunable system. Specifically, the facial muscles are hypothesized to be able to change the frequency, beam width, and directionality of the emitted sound beam in bottlenose dolphins (Tursiops truncatus). 


\section{ACKNOWLEDGEMENTS}

I would like to thank many people and organizations for their help during this project. To Dr. Ann Pabst and Bill McLellan, thank you for your endless amounts of support and encouragement and for teaching me that morphology is the foundation for learning about how animals function in their environment. Ann, thank you for being such a terrific role model and mentor. I feel lucky to have worked with such an amazing teacher and morphologist. Bill, thank you for your help with tissue sectioning and for teaching me how to look at animals from the inside-out! I admire your creativity and willingness to think “outside the box". To Dr. Sentiel Rommel, thank you for showing me another way to look at the world and for fueling my curiosity on a daily basis. Also, thank you for your help with the CAD drawings in this thesis. A special thanks to Dr. Heather Koopman for showing me that other types of connective tissues are exciting! Dr. Dillaman, thank you for introducing me to the fascinating world of histology and electron microscopy! You changed the way I think about structure and function. To Mark Gay, Photoshop extraordinaire, thank you for teaching me about tissue processing, photography, and image analysis and for being so patient with me.

I would also like to thank the UNCW Marine Mammal Stranding Program and the Virginia Aquarium Stranding Response Team for their help with sample collection. Also, thank you to the Florida Fish and Wildlife Marine Mammal Pathobiology Lab for allowing us to use your band saw and to Jane Greer, a local Wilmington artist, for making the glassware for the polarized light imaging.

To my labmates and friends, Erin Meagher, Brian Balmer, Johanna Imhoff, Marina Piscitelli, Zoey Zahorodney, Zack Swaim, Josh Yonas, Dr. Ari Friedlaender, and 
Dr. Andrew Westgate, thank you for your support and for helping me collect the data for this project. I would also like to thank my family for their endless amounts of encouragement during every phase of this adventure.

I thank the NOAA Prescott Stranding Program, the Frances P. Fensel Scholarship, the UNCW Graduate School, and the Biology Graduate Student Association for their financial support. 


\section{DEDICATION}

I would like to dedicate my thesis to all of the strong woman in my life! To my mom, Sandy Harper, and Elizabeth Watson, Brina Neustat, Lucy Steere, and Judy Clark and my grandmothers, Nancy Forsyth and Anne Steere. I admire your confidence, creativity, and willingness to tackle anything that life hands you. You taught me how to be a strong woman and stand up for what I believe in. Thank you for your support and love. 


\section{LIST OF TABLES}

Table Page

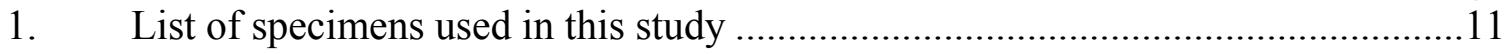

2. The orientation and hypothesized action of each facial muscle that inserts into the right caudal melon and the main body of the melon...............................53

3. The orientation and hypothesized action of each facial muscle that inserts into the left caudal melon 
Figure

\section{LIST OF FIGURES}

1. Right lateral (A) and dorsal (B) view of a Tursiops truncatus skull .....................2

2. Lateral view of the nasal passages and melon of a Tursiops truncatus, highlighting its position relative to the nasal passages and the skull.... 3

3. X-ray Computed Tomography image (A) and corresponding schematic (B) of a parasagittal slice through a Delphinus delphis head.

4. Lateral view (A) of the Tursiops truncatus forehead showing the positions of transverse sections (B and $\mathrm{C}$ )

5. Sagittal section of the Tursiops truncatus forehead, showing the caudal melon and the main body of the melon.

6. Polarized light image of a parasagittal section of the caudal Tursiops truncatus melon, highlighting the shape of the stem and cup of the right caudal melon

7. Polarized light image of frontal section of the Tursiops truncatus melon, highlighting the regions of the melon and their positions in the forehead.

8. Polarized light image of a transverse section of the caudal Tursiops truncatus melon, highlighting the branching pattern of the caudal melon and the asymmetry between the right cone and left branch

9. Polarized light image of transverse section of the Tursiops truncatus caudal melon

10. Polarized light image of a sagittal section through the Tursiops truncatus melon, highlighting the left cup of the left caudal melon

11. Transverse section through the rostral end of the Tursiops truncatus melon, a few centimeters from the apex of the forehead

12. Transverse section through the Tursiops truncatus melon, approximately $10 \mathrm{~cm}$ from the apex of the forehead

13. Transverse section through the Tursiops truncatus melon, at the level of the supraorbital notch.

14. Transverse section through the Tursiops truncatus melon, a few centimeters rostral to the blowhole 
15. Transverse section through the Tursiops truncatus melon, just rostral to the blowhole

16. Polarized light image of a transverse section through the Tursiops

truncatus melon, at the origin of the nasal plug muscle

17. Polarized light image of a transverse section through the Tursiops truncatus melon, at the origin of the nasal plug muscle

18. Right lateral (A) and dorsal (B) view of a Tursiops truncatus skull illustrating the origin and orientation of the oblique rostral muscle

19. Frontal section of the ventral portion of the main body of the melon of a Tursiops truncatus

20. Polarized light image of oblique frontal section through the ventral portion of the main body of the melon of a Tursiops truncatus

21. Frontal section through the Tursiops truncatus melon, a few centimeters deep to the blowhole.

22. Right lateral (A) and dorsal (B) view of a clay model of the nasal plug and associated muscle and connective tissue

23. Polarized light image of a sagittal section through the caudal end of the Tursiops truncatus melon, highlighting the floor and dorsal roof of the nasal plug

24. Frontal section through the Tursiops truncatus melon, just ventral to the right dorsal bursa.

25. Polarized light image of a sagittal section through the caudal end of the Tursiops truncatus melon, highlighting the tendons of the embedded muscles in the dorsal roof of the nasal plug

26. Polarized light image of a transverse section through the Tursiops truncatus caudal melon, just at the boundary between the stem of the melon and the ventral surface of the cup of the melon

27. Transverse section of the Tursiops truncatus forehead, approximately one centimeter rostral to the blowhole

28. Average height and width of the stem and cone of the right caudal melon in a bottlenose dolphin, Tursiops truncatus 


\section{INTRODUCTION}

Dolphins sense their surroundings by emitting high frequency echolocation signals from their forehead and by receiving and processing the returning echoes (Norris, 1969). The melon is a specialized lipid structure within the dolphin forehead that functions in the transmission of echolocation signals. The melon's ability to transmit sound has been attributed in part to its unique fatty acid composition (Litchfield et al., 1971; Varanasi and Malins, 1972; Litchfield et al., 1975; Malins and Varanasi, 1975; Varanasi et al., 1982; Cranford et al., 1996; Soldevilla et al., 2005). The heterogeneous composition and distribution of the so-called "acoustic fats" within the melon serve to focus the sound in the forward direction (e.g. Norris and Harvey, 1974; Varanasi et al., 1982). These acoustic fats also allow for the efficient transmission of pneumatically produced sound into water (Norris and Harvey, 1974; Au, 1993, Cranford et al., 1996). The facial muscles and connective tissue fibers surrounding the melon have also been hypothesized to help guide sound through the melon and into the surrounding water (Norris and Harvey, 1974). This study investigates the facial muscles and their tendons that act upon the melon and adjacent connective tissues in bottlenose dolphins (Tursiops truncatus).

The melon rests on the dorsal surface of the bony rostrum and lies rostral to the internal bony nares (Figs. 1, 2). The cetacean skull has been described as "telescoped” (Miller, 1923) because a subset of facial bones are elongated rostrally and extended dorsally over the rostral aspect of the braincase. The dorsal aspect of the bony rostrum, which is formed by the maxillae and premaxillae, is elongated and bilaterally symmetrical. The maxillae extend caudally from the tip of the rostrum and spread over the frontal bones in a fan shape to create the most superficial layer of the rostral wall of the cranial vault (Rommel, 1990). The premaxillae lie along the dorsomedial surface of the maxillae and also extend caudally to form the rostrolateral 

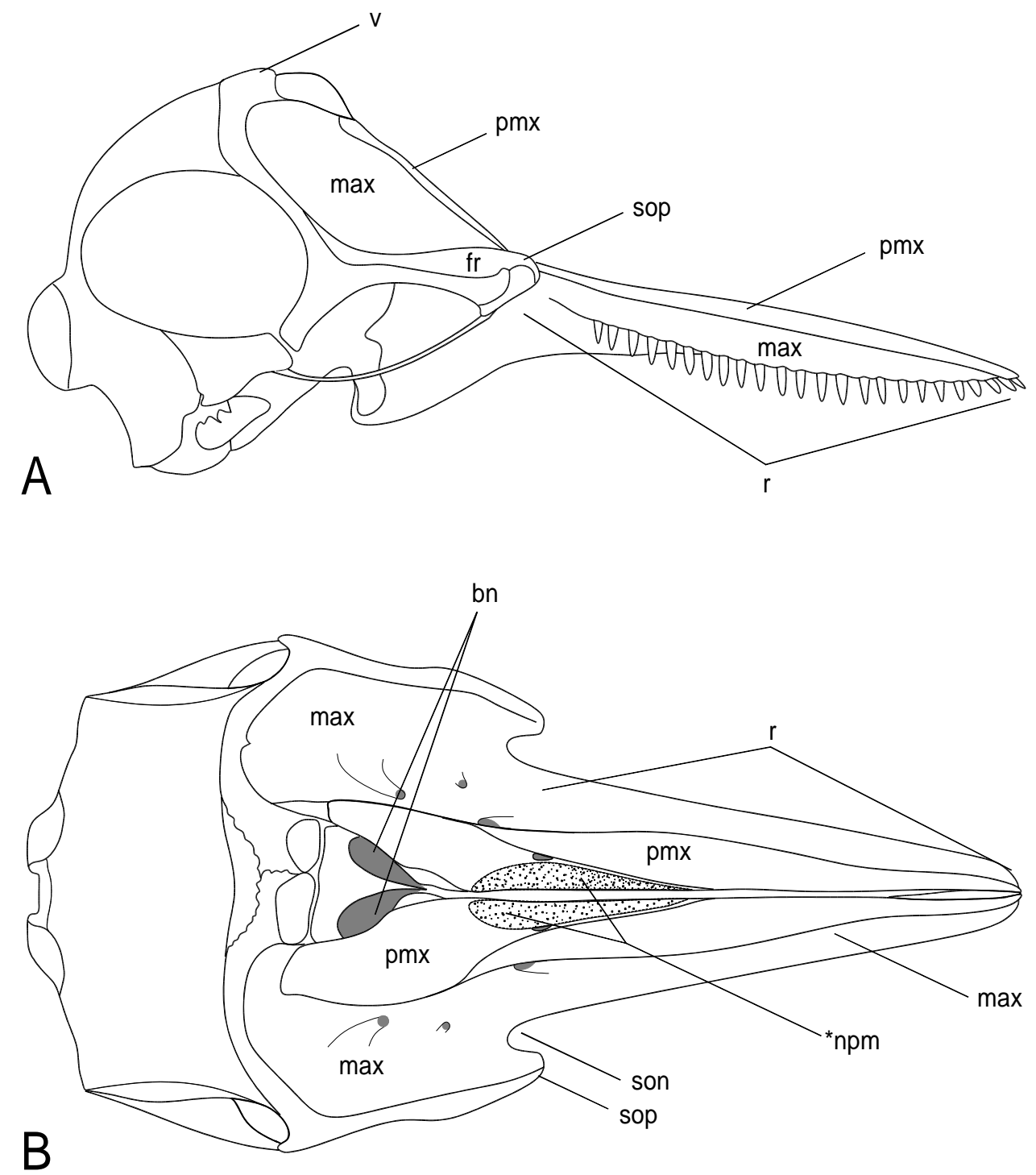

Fig. 1. Right lateral (A) and dorsal (B) view of a Tursiops truncatus skull (adapted from Rommel, 2006, p. 193). bn, bony nares; fr, frontal; max, maxillae; pmx, premaxillae; r, rostrum; son, supraorbital notch; sop, supraorbital process; *npm, origin of the nasal plug muscle; v, vertex. 


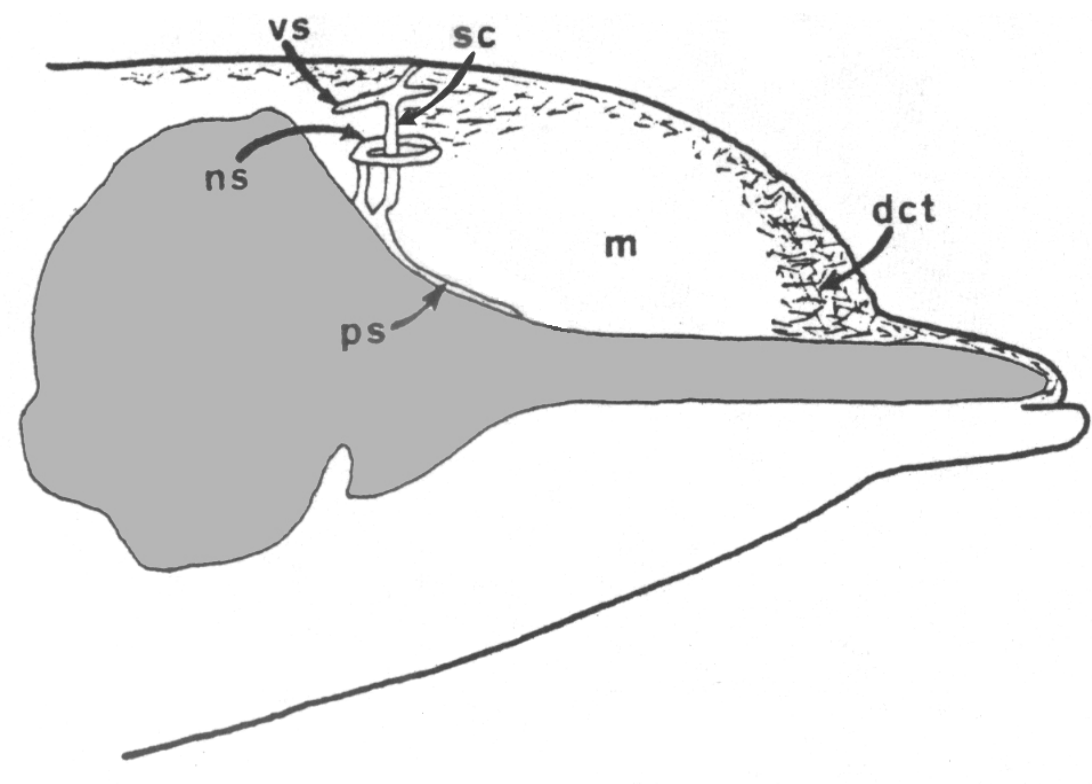

Fig. 2: Lateral view of the nasal passages and melon of a Tursiops truncatus, highlighting its position relative to the nasal passages and the skull (adapted from the Mead, 1975, p. 59). dct, dense connective tissue; m, melon; ns, nasofrontal sac; ps, premaxillary sac; sc, spiracular cavity; vs, vestibular sac. Skull is highlighted in gray. 
edge of the internal bony nares (Lawrence and Schevill, 1956; Rommel, 1990). In contrast to the rostrum, the caudal portion of the skull is rostro-caudally compressed and is bilaterally asymmetrical. Specifically, the caudal portion of the premaxillae is larger on the right than on the left. The internal bony nares, which typically occupy a rostral position in the mammalian head, are positioned dorsocaudally and the right naris is being larger than the left (Heyning and Mead, 1990; Rommel, 1990). These bony features act as the hard tissue scaffolding for the melon and serve as the origin for the facial muscles that act upon the melon (e.g. Mead, 1975).

The nasal passages form the caudal boundary of the melon. The nasal passages in dolphins are complex and include a series of paired, blind diverticulae that extend from a common passageway called the spiracular cavity (Lawrence and Schevill, 1956; Mead, 1975; Cranford et al., 1996) (Fig. 2). These paired diverticulae include the vestibular sacs, the nasofrontal sacs, and the premaxillary sacs. The broad, flat vestibular sacs lie lateral to the spiracular cavity and lie just deep to the blowhole. Ventral to the vestibular sacs lie the nasofrontal sacs, which are paired U-shaped tubes placed like "parentheses” around the spiracular cavity. The spiracular cavity continues ventrally from the nasofrontal sacs and diverges into the left and right internal nares. The premaxillary sacs, which open into the spiracular cavity, are flattened, paired diverticulae that lie rostral and ventral to the internal nares.

The intimate spatial relationship between the melon and the nasal passages is critical to its function in sound transmission because the echolocation sound generators are embedded within the walls of the spiracular cavity. The odontocete echolocation sound generators were first described by Cranford et al. (1996) using X-ray Computed Tomography (CT). These authors named the sound generators the monkey lip dorsal bursae (MLDB) complex, and 
described them as small ellipsoid fat bodies, each wrapped in a connective tissue sheath (Fig. 3). There is a posterior and anterior dorsal bursa on the right and left side of the spiracular cavity. Each dorsal bursa lies within a small, lip-like structure, called monkey lip (Poughet and Beauregard, 1885 as cited in Cranford et al., 1996). The surface of each monkey lip is a darkly pigmented layer forming a series of ridges and grooves, oriented in the dorsoventral direction. Each posterior and anterior pair of monkey lips are pressed tightly together and seal off the dorsal portion of the spiracular cavity.

The caudal melon lies just rostral to the right and left MLDB complex (Fig. 3). In bottlenose dolphins (Tursiops truncatus), the caudal melon is formed by two asymmetric branches of fat (Cranford et al., 1996). The right branch is a large channel of fat, situated along the midline of the forehead, and it connects directly to the right anterior dorsal bursa. The left branch of the caudal melon diverges from the right branch and ends blindly in a mass of connective tissue and muscle, just rostral to the left MLDB complex (Cranford et al., 1996).

The caudal melon is continuous with the main body of the melon (Fig. 3). The main body of the melon gradually decreases in cross-sectional area until it terminates just caudal to the apex of the forehead. X-ray CT images demonstrated that the main body of the melon is an elliptical, bulbous shaped structure surrounded by dense connective tissue (Cranford et al., 1996; McKenna, 2005). However, the identities of the surrounding connective tissues and how they are connected to the melon are not yet known.

Cranford et al. (1996) proposed that sound is produced when pressurized air passing through the nares from the lower respiratory tract is passed over the MLDB complex. The flow of air causes the monkey lips to vibrate, which in turn, sets the dorsal bursae in motion. Thus, pressurized air is used to create vibrations in adjacent fatty soft tissue. These authors also 

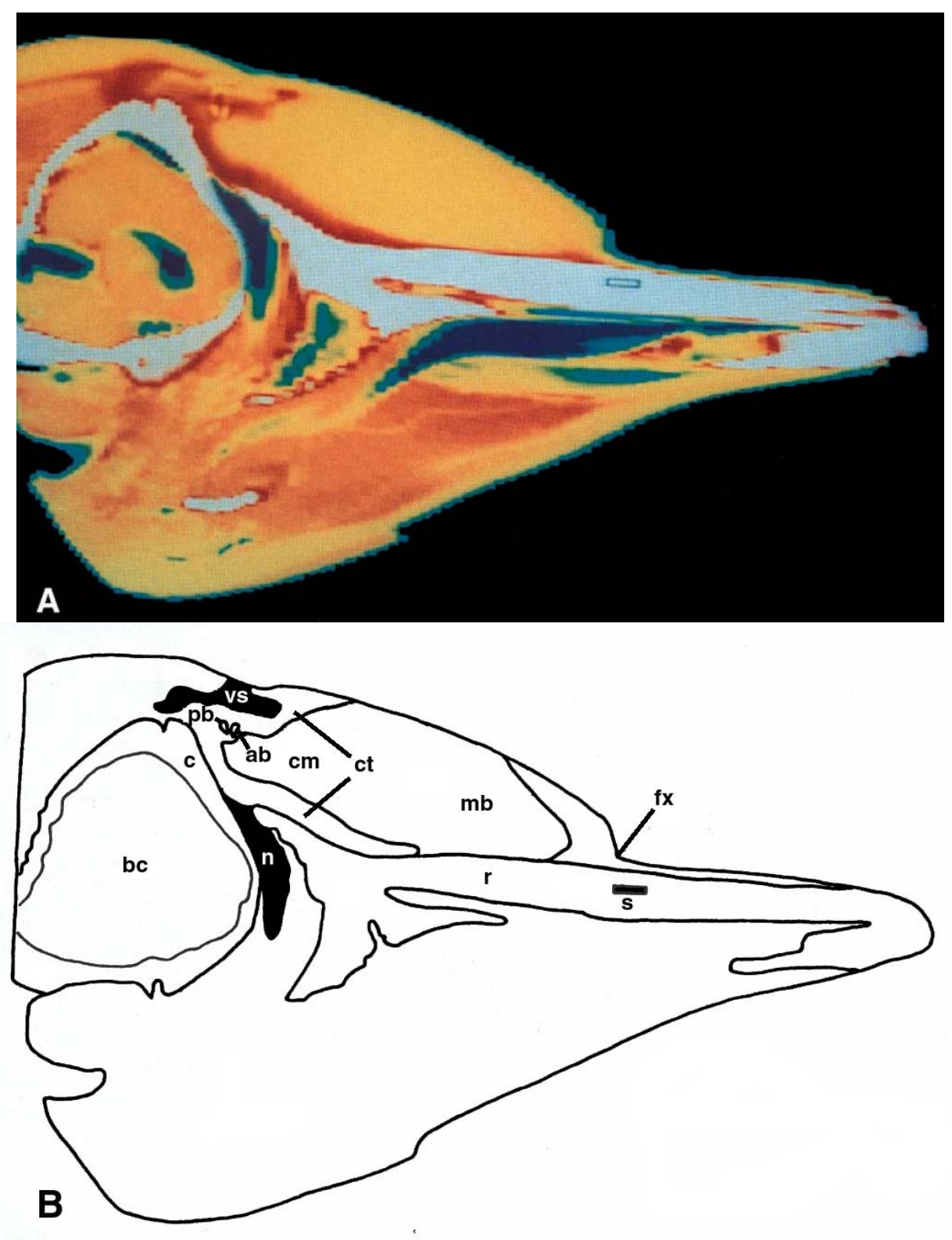

Fig. 3. X-ray Computed Tomography image (A) and corresponding schematic (B) of a parasagittal slice through a Delphinus delphis head (Cranford et al., 1996, p. 243). ab, anterior bursa; bc, brain; c, cranium; cm, caudal melon; ct, connective tissue theca; fx, forehead apex; $\mathrm{mb}$, main body of the melon; n: naris; pb, posterior bursa; r, bony rostrum; s, scale $(1.5 \mathrm{~cm})$; vs, vestibular sac. 
hypothesized that the tissue-borne vibrational energy produced by the MLDB complex travels through the caudal branch of the melon, into the melon, and then into the surrounding aquatic environment.

Norris and Harvey (1974) proposed that that facial muscles may play a role in guiding sound through the melon because a subset of these muscles appear to be intimately connected to this specialized lipid structure. The ventral floor of the melon, for example, is formed by facial muscle along its entire length (Fig. 4). Along the rostrum, the rostral muscles lie ventrolaterally to the melon and can be separated into distinct lateral and medial portions (Mead, 1975). Mead (1975) gave separate names to these portions of rostral muscle because the fibers of each muscle group have different orientations. The lateral portion, which is a rostral extension of the superficial facial muscles (pars posteroexternus, pars intermedius, pars anteroexternus, pars posterointernus; Mead, 1975), originates on the maxillae and inserts primarily into the lip and lateral region of the melon. The medial portion of the rostral muscle is an extension of the deep caudal facial muscles (pars anterointernus; Mead, 1975), which originates on the maxillae and inserts into the melon. To date, the orientations of the tendons of the rostral muscles, and how they insert into the fatty melon and/or the surrounding dermal tissue has not been described. The tendons of the rostral muscles are difficult to see during gross dissection, because they are white connective tissue fibers embedded in white fat. Since the tendons of these facial muscles have not been previously described, their actions have not yet been determined.

The nasal plug muscle also grades into the melon and forms the ventrocaudal boundary of the melon (Fig. 4c). Mead (1975) described the nasal plugs as rounded, irregularly-shaped soft tissue structures that serve to occlude the bony nares. During inspiration and expiration, the nasal plugs move rostrally to permit air flow and then return to their resting position to form a 

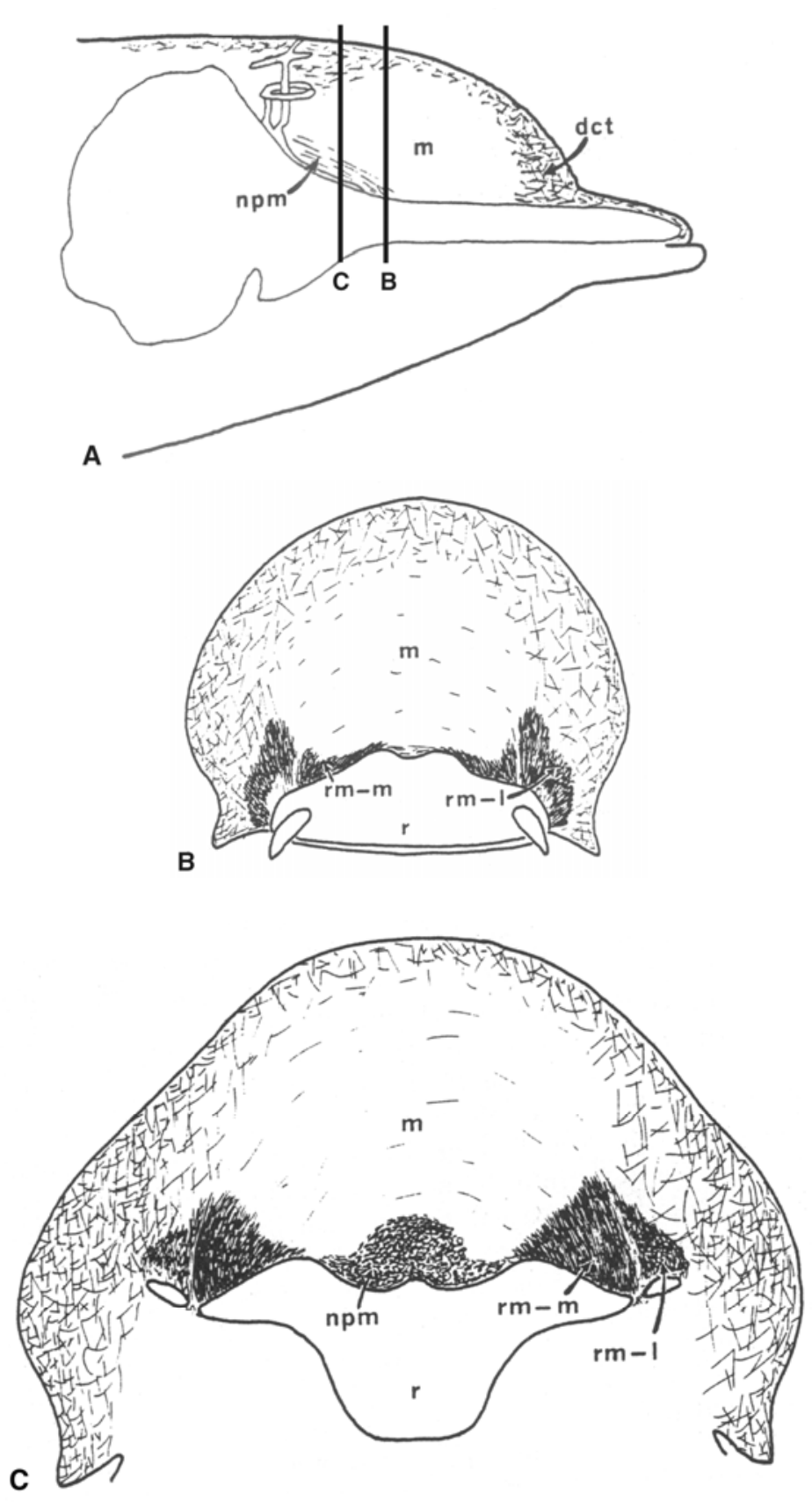

Fig. 4. Lateral view (A) of the Tursiops truncatus forehead showing the positions of transverse sections (B and C). (B) and (C) are sectioned $14 \mathrm{~cm}$ and $18 \mathrm{~cm}$ from the tip of the rostrum, respectively (adapted from Mead, 1975, p. 13). dct, dense connective tissue; m, melon; npm, nasal plug muscle; r, rostrum; rm-l, lateral portion of rostral muscle; rm-m, medial portion of rostral muscle. 
tight, occlusive seal over the internal nares. The nasal plug muscle, which originates from the premaxillae, is responsible for the rostral movement of the nasal plugs, but it is also directly connected to the ventral floor of the melon (Mead, 1975; Heyning, 1989). The orientations of the nasal plug muscle fibers, and how they are tendinously connected to the melon, are not yet known.

To date, the location of the melon relative to the facial bones of the skull, nasal passages, and facial muscles has been well defined through gross anatomical studies (Howell, 1930; Lawrence and Schevill, 1956; Mead, 1975; Heyning, 1989), and the shape of the melon and its connections to the MLDB complex have been defined using X-ray CT scanning (Cranford et al., 1996; McKenna, 2005). The tendinous connections between the facial muscles and the melon, the geometries of the connective tissues within the melon (sensu Wainwright et al., 1976), and the discrete connections between the melon and the surrounding dermal tissues are not yet known. Thus, the role of the facial muscles in guiding sound through the melon (Norris and Harvey, 1974) has not been fully evaluated. Therefore, the goal of this study is to use polarized light imaging, in conjunction with standard gross dissection and serial sectioning techniques, to describe the morphology of the melon and its connections to the facial muscles and dermal tissues in the bottlenose dolphin (Tursiops truncatus). These observations will be used to generate hypotheses regarding the specific roles of the facial muscles in the propagation of echolocation signals through the dolphin forehead. 


\section{MATERIALS AND METHODS}

Specimens

Heads were used from Atlantic bottlenose dolphins, Tursiops truncatus, (Smithsonian Institution Condition Code 1, 2, and 3; Geraci and Lounsbury, 2005) stranded along the coasts of Virginia and North Carolina (Table 1). Although caracasses of moderate freshness (Code 3) were used in this study, the muscles and connective tissues within the head were in good condition. All specimens used for this study were collected by the Virginia Aquarium and Marine Science Center (VAQS) and the UNCW Marine Mammal Stranding Program under Federal Letters of Authorization and under UNCW IACUC \#2003-013 and \#2006-015.

\section{Gross Examination of the Bottlenose Dolphin Forehead}

Standard gross dissection and serial sectioning techniques were used to investigate the relationships between the melon, MLDB complex, facial muscles, surrounding blubber, and skull. During all gross dissections (described below), notes and drawings were made. Digital photographs were also taken with a Nikon D100 and stored as non-compressed image files (Tagged Image File Format, 300 pixels per inch) for later analysis. Nomenclature used in this study to describe anatomical structures followed Mead (1975), Heyning (1989), Rommel (1990), and Cranford et al. (1996).

\section{Standard Gross Dissection Techniques}

Gross dissections ( $n=8$ ) were conducted as superficial to deep investigations of soft and hard tissues, aimed at understanding the three dimensional morphology of the entire forehead (Table 1). Blubber was removed from the caudo-lateral sides of the forehead and the facial 
TABLE 1. List of specimens used in this study.

\begin{tabular}{|c|c|c|c|c|c|}
\hline $\begin{array}{l}\text { Dissection } \\
\text { Type }\end{array}$ & Field Number & $\begin{array}{l}\text { S.I. } \\
\text { Code }\end{array}$ & $\begin{array}{c}\text { Total } \\
\text { Length (cm) }\end{array}$ & Sex & $\begin{array}{l}\text { Section } \\
\text { Plane }\end{array}$ \\
\hline \multicolumn{6}{|l|}{ Gross } \\
\hline \multirow[t]{8}{*}{ Dissection } & AJW 002 & 2 & 194 & M & \\
\hline & WAM 627 & 2 & 194 & M & \\
\hline & VMSM 20041079 & 2 & 195 & $\mathrm{~F}$ & \\
\hline & CJH 003 & 2 & 229.5 & $\mathrm{~F}$ & \\
\hline & VAQS 20061053 & 3 & 254.5 & $\mathrm{M}$ & \\
\hline & AJW 001 & 2 & 274 & M & \\
\hline & WAM 631 & 2 & 275 & $\mathrm{~F}$ & \\
\hline & WAM 600 & 3 & 291 & M & \\
\hline \multicolumn{6}{|l|}{ Serial } \\
\hline \multirow[t]{3}{*}{ Sections } & WAM 595 & 3 & 180 & M & Frontal \\
\hline & VAQS 20051086 & 2 & 195.4 & M & Transverse \\
\hline & WAM 608 & 2 & 259 & $\mathrm{~F}$ & Sagittal \\
\hline \multicolumn{6}{|l|}{ Thin Serial } \\
\hline \multirow[t]{3}{*}{ Sections * } & BCB 002 & 2 & 171 & M & Sagittal \\
\hline & VAQS 20051118 & 2 & 189 & M & Frontal \\
\hline & WAM 601 & 1 & 281 & M & Transverse \\
\hline
\end{tabular}

S.I. Code: Smithsonian Institution Code (see Geraci and Lounsbury, 2005)

* sections were used for polarized light imaging 
muscles were carefully separated into their distinct portions. The caudal facial muscles were bisected or serially removed to investigate the morphology of the spiracular cavity and its connections to the nasal sac system (vestibular sacs, nasofrontal sacs, premaxillary sacs). The right and left MLDB complexes were identified and their positions relative to the caudal melon, nasal plug muscle, and the nasal sac system were also investigated. Since the melon is a fatty structure and is intimately connected to dense connective tissue and muscle, it cannot easily be separated from other structures in the head. Consequently, during gross dissection, the melon and the rostral muscles were serially sectioned either tangentially to the surface of the forehead or along the transverse, sagittal, or frontal body plane. These gross dissections permitted the connections between the melon and other structures within the forehead to be physically manipulated and examined in multiple dimensions.

\section{Serial Sectioning Techniques}

To further examine the boundaries of the melon and the spatial relationships between the melon and other soft tissues, frozen bottlenose dolphin heads $(n=3)$ were serially sectioned in the transverse, sagittal, and frontal planes using a commercial grade band saw (Model \#5801; Hobart Corporation; Troy, Ohio ) (Table 1). The soft tissues of the forehead and skull were sectioned along the transverse plane, whereas only the soft tissues of the forehead were sectioned along the sagittal and frontal body planes. In these two planes, the soft tissue of the forehead was carefully removed from the skull, completely wrapped in Saran Wrap ${ }^{\circledR}$ to prevent desiccation, and then refrozen at $-20^{\circ} \mathrm{C}$ prior to sectioning.

To prevent tissue deformation during sectioning and to ensure proper alignment of the head along each section plane, the frozen heads were positioned within a cradle made of hard 
foam and placed in a reinforced cardboard box. Insulating spray-foam was used to fix the heads within the box, which was then frozen at $-20^{\circ} \mathrm{C}$ until sectioning. At the onset of sectioning, the edge of the cardboard cradle was aligned with the saw guide, which helped to ensure that each section was cut along the desired body plane. Each section (approximately 1-1.5 centimeters in thickness) was quickly re-frozen on a flat metal plate lined with Saran Wrap ${ }^{\circledR}$ and then vacuum sealed in protective plastic or wrapped completely in Saran Wrap ${ }^{\circledR}$ to prevent desiccation until photography. Each section was thawed and photographed. A scale bar, placed at the same height as the section, was included in each image.

\section{Polarized Light Imaging}

Polarized light imaging was also used in this study to visualize the orientations and trajectories of the muscle and connective tissue fibers in the bottlenose dolphin forehead along transverse, sagittal, and frontal planes ( $\mathrm{n}=3$, one head per plane) (Table 1). The soft tissue of the forehead was carefully removed from the dorsal skull, completely wrapped in Saran Wrap ${ }^{\circledR}$ to prevent desiccation, and placed back on the skull to permit the tissue to assume its in situ posture. The soft tissue of the forehead and the skull were then refrozen at $-20^{\circ} \mathrm{C}$.

To facilitate thin-sectioning, each forehead was first cut into multiple blocks along an orthogonal body plane. For example, for the transverse sections, the forehead was sectioned into six blocks, each approximately five centimeters thick. Each block, which provided a flat surface for sectioning, was then thin-sliced on a Hobart meat slicer (Model \#1612E, Hobart Corporation; Troy, Ohio) into 0.8-1.0 millimeter sections. A subset of these thin sections was selected for polarized light imaging based upon the presence of structures of interest in the section and the physical integrity of the section. 
These sections were then dehydrated in an ascending series of acetone baths (50\%, 70\%, 90\%, 100\%, 100\%) and cleared with methyl salicylate (Presnell and Schreibman, 1997;

Hamilton et al., 2004). Because water was removed during the dehydration process, the thin sections decreased slightly in size. The amount of distortion was dependent on the section plane. There was little deformation (less than one centimeter in width and length) in the sections sliced in the transverse and frontal body planes. There are highly organized fiber arrays that exist within these body planes, which probably contributed to the sections overall integrity during the dehydration and clearing process. The amount of distortion was greatest for the sections sliced along the sagittal body plane, where less discrete fiber populations reinforced sections cut along this plane.

Polarized light was used to visualize the birefringent collagen fibers and muscle fibers within each thin section. Due to the large size of each section, a special polarized lighting system was required. The sections were placed between two plane polarizing filters. The first polarizer, a large piece of polarized film (17’x 19’; Edmund Optics Incorporated; Barrington, NJ), was placed on a light table. The sample, which was bathed in methyl salicylate and placed in a closed, glass container, was placed on the polarizing film. The sample was then imaged with a tripod-mounted, Nikon D100 camera equipped with a polarized lens filter which acted as the analyzer. Each section was rotated six times to illuminate connective tissue fibers at multiple orientations within the section plane.

All section photographs were stored as non-compressed image files (Tagged Image File Format, 300 pixels per inch) and viewed in Adobe Photoshop (version 5.0.2). In all sections, the origin, orientation, and insertion of the connective tissue fibers and muscle fibers were qualitatively investigated. All quantitative measurements were determined using Image $\mathrm{J}$ 
(version 1.37; Wayne Rasband; NIH freeware). The plates in this study were also created in Adobe Photoshop (version 5.0.2).

\section{RESULTS}

The following is a description of the melon in bottlenose dolphins (Tursiops truncatus) and the facial muscles and tendons that act upon it. This study will redefine the regions of the melon to include the cup, stem, cone, branch, and main body of the melon based upon regionally specific morphologies and connections to facial muscles. The origin, orientation, and insertion of the rostral muscles, pars anterointernus, and nasal plug muscle will also be described. The morphology presented here is based upon observations from subadult and adult bottlenose dolphins. The shape of the melon and the muscle-tendon geometries were similar between these two age classes and across individuals.

The orientation and geometry of the facial muscles and tendons will be used to make predictions about the imposed directional load caused by the facial muscles. The present study acknowledges that contraction of a muscle oriented in one body plane may affect the overall shape and/or internal pressure of the melon. The imposed directional load will be hypothesized in the Results section and the combined effects of facial muscle contraction and their effect on sound transmission will be described in the Discussion section.

The Shape of the Melon

The melon is a specialized lipid structure that lies dorsal to the bony rostrum and rostral to the MLDB complexes. Along its length, the melon's cross sectional area and, thus, its three dimensional shape varies. The melon has been described to have two regions - the main body of 
the melon and the caudal melon (Cranford et al., 1996; McKenna, 2005) (Fig. 5). The main body of the melon extends the melon apex, which lies caudal to the apex of the forehead, to the level of the origin of the nasal plug muscle. In this region, the melon is shaped as a rounded, bulbous structure. The ventral surface of the main body is flattened and it rests on the premaxillae and the maxillae. Its rostral end is tapered and lies just caudal to the apex of the forehead (Fig. 5). The cross-sectional shape of the main body of the melon is hemispherical and symmetrical. From its apex to the origin of the nasal plug muscle, the main body of the melon gradually increases in height and width. At the origin of the nasal plug muscle, the main body of the melon achieves its maximum height and width and it is continuous with the caudal melon (Fig. 5).

The asymmetric caudal melon extends from the origin of the nasal plug muscle to the anterior dorsal bursae (Fig. 5). The shape and boundaries of the caudal melon are difficult to visualize in the serial sections because the white fat is intimately connected to the white connective tissue fibers in the forehead. When this region is imaged under polarized light, the shape of the caudal melon becomes clear. The following description will begin by examining the right side of the caudal melon.

The right caudal melon is a continuous channel of fat that extends from the origin of the nasal plug muscle to the right anterior dorsal bursa. It can be subdivided into three regions, termed here as the cone, stem, and cup (Fig. 6, 7). Each of these regions varies in threedimensional shape and is acted upon by different facial muscles (see later descriptions). The cone of the right caudal melon is shaped as a caudally tapered, truncated cone, oriented along the midline of the forehead (Fig. 6). Its broad base is located at the origin of the nasal plug muscle where it is continuous with the main body of the melon. From the origin of the nasal plug 


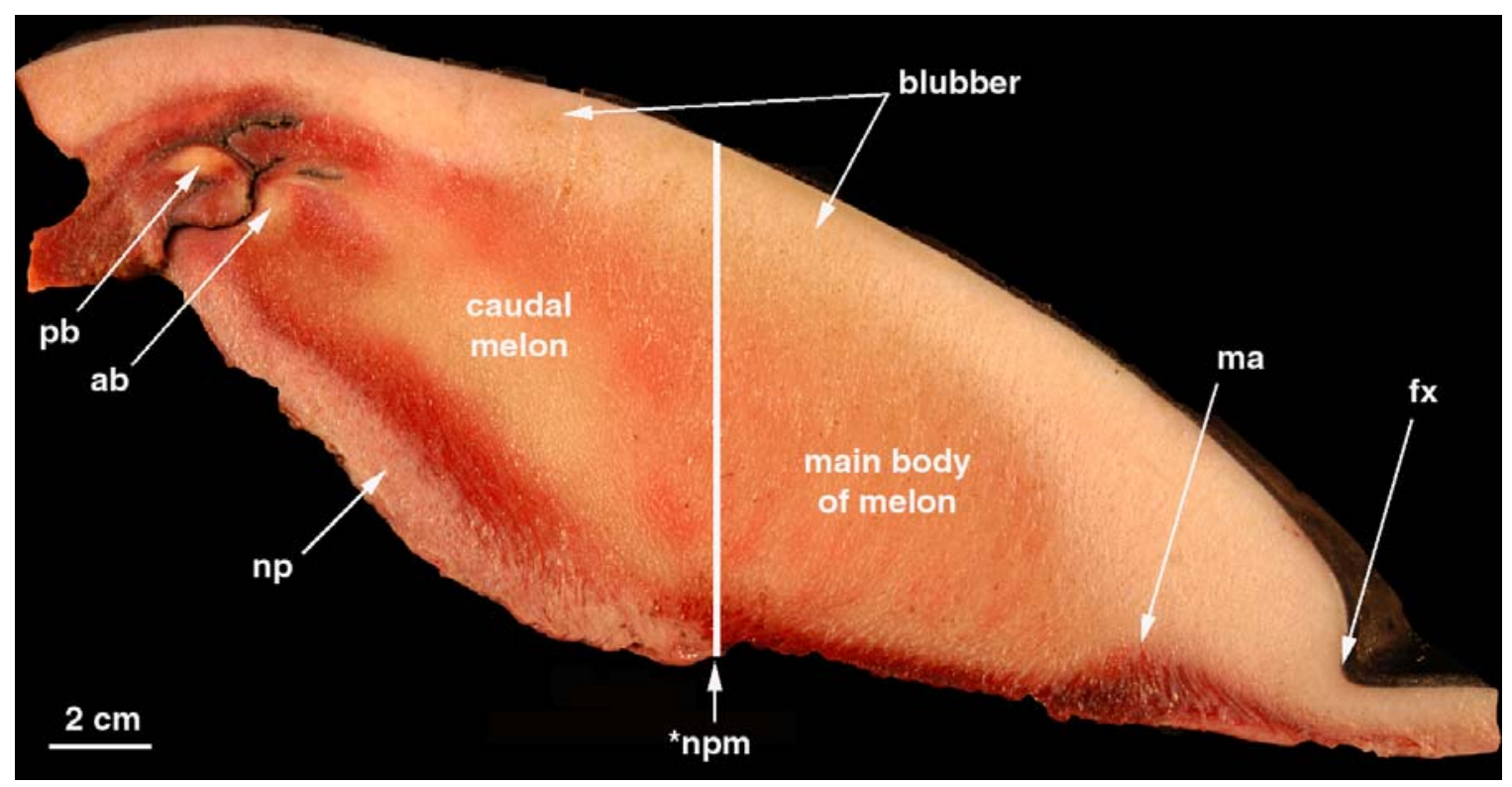

Fig. 5. Sagittal section of the Tursiops truncatus forehead, showing the caudal melon and the main body of the melon. This section is taken to the right of the blowhole. Rostral is to the right. The skull was removed prior to sectioning. ab, anterior dorsal bursa; $\mathrm{fx}$, forehead apex; ma, melon apex; np, nasal plug; pb, posterior dorsal bursa; *npm, origin of nasal plug muscle. 


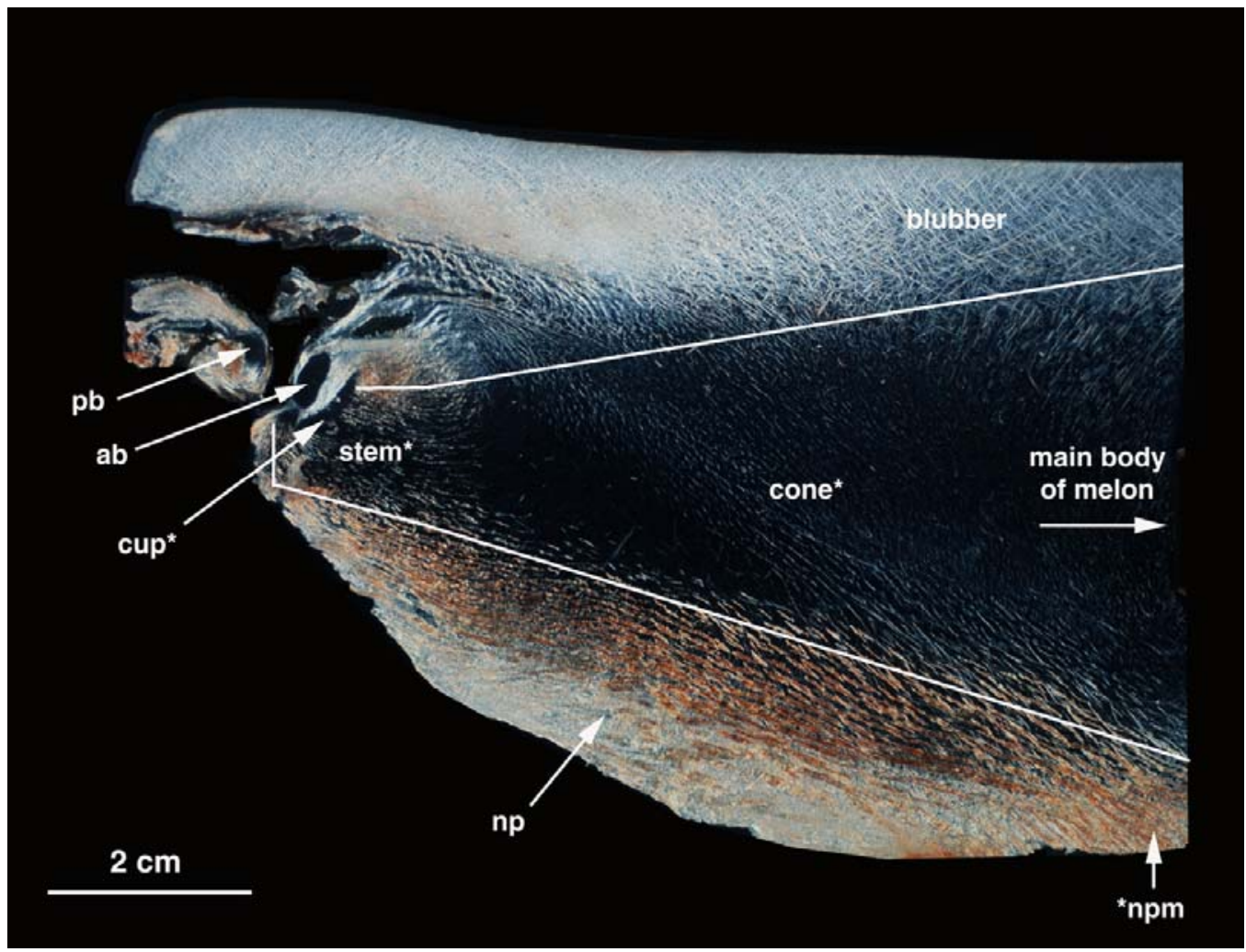

Fig. 6. Polarized light image of a parasagittal section of the caudal Tursiops truncatus melon, highlighting the shape of the stem and cup of the right caudal melon. This section is taken to the right of the blowhole. Rostral is to the right. ab, anterior dorsal bursa; np, nasal plug; *npm, origin of the nasal plug muscle; pb, posterior dorsal bursa. The asterisks $\left(^{*}\right)$ of the cup, stem, and cone indicate that these are the three regions of the right caudal melon. 


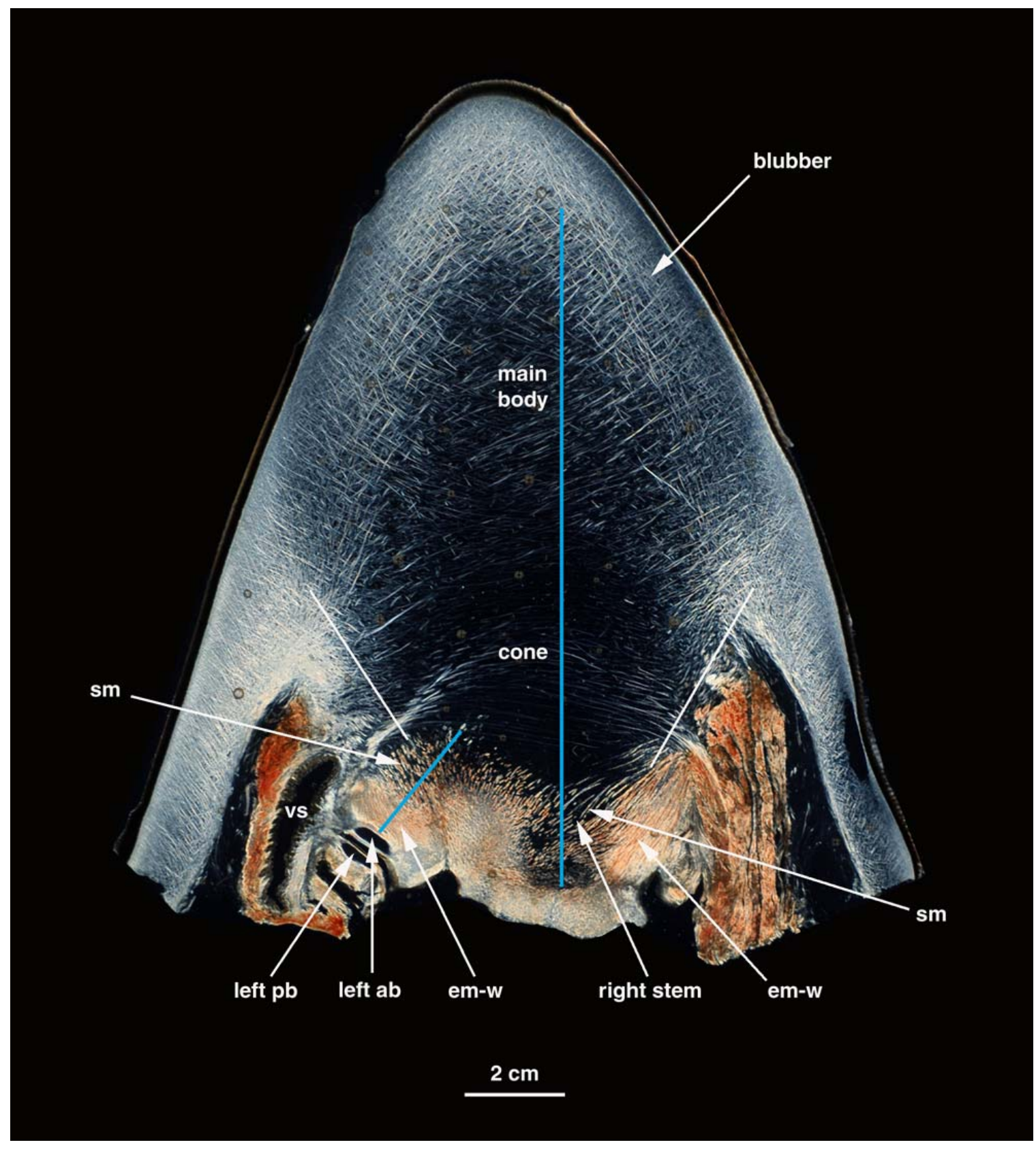

Fig. 7. Polarized light image of frontal section of the Tursiops truncatus melon, highlighting the regions of the melon and their positions in the forehead. This section is taken a few centimeters deep to the blowhole. Rostral is towards the top of the page. The vertical blue line demarcates the axis of the right caudal melon, which is slightly to the right of the midline. The angled blue line demarcates the axis of the left branch. The white lines point to the lateral boundaries of the cone of the melon. ab, anterior dorsal bursa, em-w, embedded muscle of the lateral wall of the nasal plug; pb, posterior dorsal bursa; sm, suspended nasal plug muscle; vs, vestibular sac. 
muscle to the level of the supraorbital notch (Fig. 1), the base of the cone has a large diameter and is symmetrical in cross-sectional shape. Further caudally, the cone gradually decreases in cross-sectional area. The cone terminates at the stem, which is defined here as the point at which the caudal melon is completely surrounded by the muscle of the nasal plug (Fig. 7). The stem is a narrow tube of fat that is oriented horizontally in the forehead and rests within the boundaries of the nasal plug. The stem of the melon is connected to the cup of the melon (Fig. 6). The cup also lies within the nasal plug and envelopes the ventrorostral surfaces of the connective tissue sheath surrounding the right anterior dorsal bursa. Thus, the right anterior dorsal bursa is directly connected to the main body of the melon via the cup, stem, and cone of the right caudal melon.

There is also a left branch of the caudal melon in bottlenose dolphins (Tursiops truncatus). At the level of the supraorbital notch, the left caudal melon diverges from the cone (Fig. 7). It is shaped as a small branch of fat with an oval cross-sectional shape (Fig. 8). The left branch extends laterally relative to the midline and is in-line with the left anterior dorsal bursa (Fig. 7). Unlike the right caudal melon, the left branch does not appear to connect directly to the left anterior dorsal bursa. Instead, this fatty branch ends blindly in the connective tissue and muscle associated with the nasal plug (Figs. 7, 9). Like the right side, though, the left caudal melon has a small cup of fat which envelopes the ventrorostral surfaces of the connective tissue sheath surrounding the left anterior dorsal bursa (Fig. 10). The left anterior dorsal bursa occupies a more ventrolateral position relative to the right dorsal bursa.

In summary, the caudal melon in bottlenose dolphins (Tursiops truncatus) is bilaterally asymmetrical. The right caudal melon consists of the cone, stem, and cup and the left caudal melon consists of a separate branch and an isolated cup. The right caudal melon forms a 


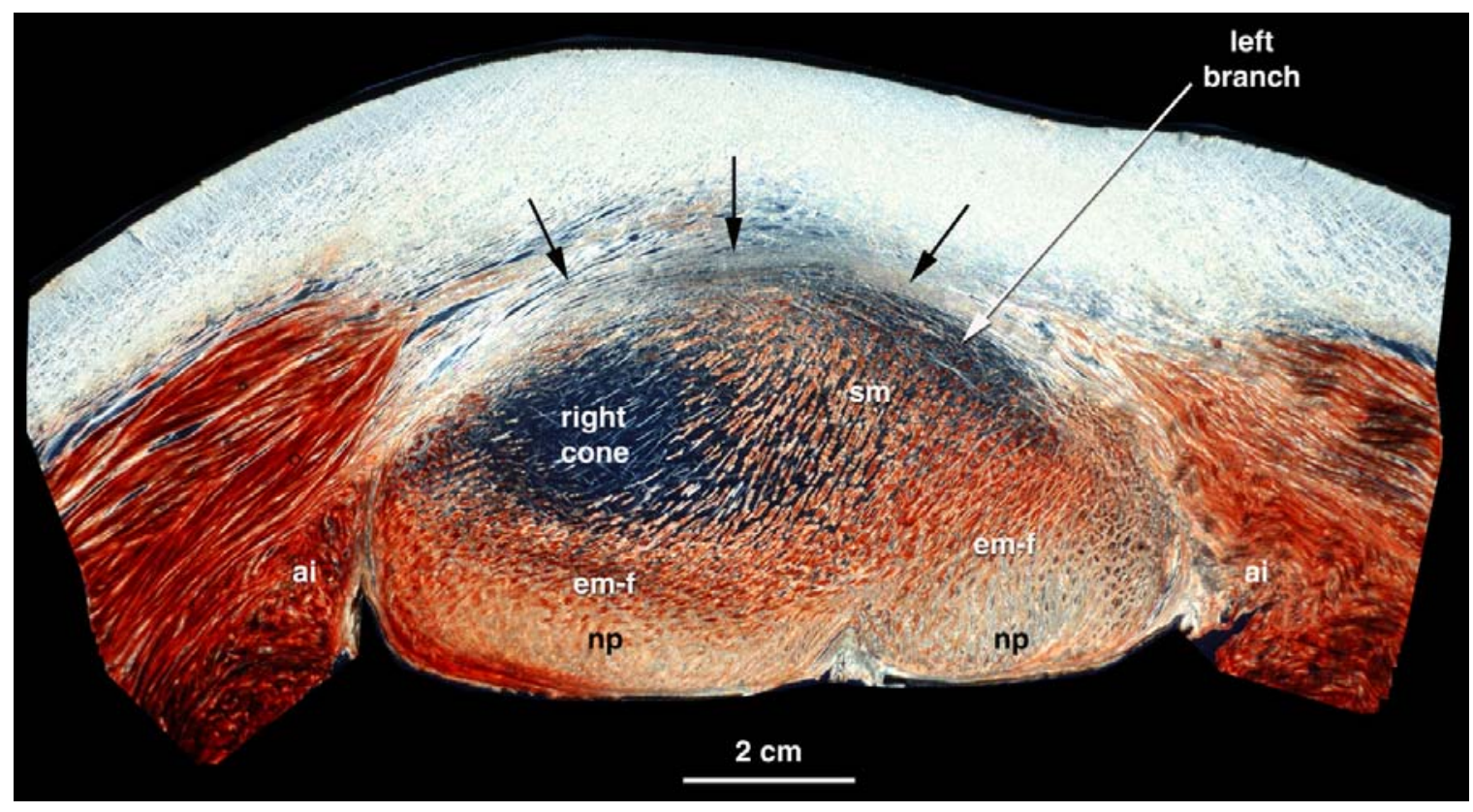

Fig. 8. Polarized light image of a transverse section of the caudal Tursiops truncatus melon, highlighting the branching pattern of the caudal melon and the asymmetry between the right cone and left branch. This section is taken at the level of the supraorbital notch. Rostral surface is facing the reader. ai, pars anterointernus muscle; em-f, embedded muscle of the floor of the nasal plug; np, nasal plug; sm, suspended nasal plug muscle. The black arrows point to the tendons of the pars anterointernus muscle. 


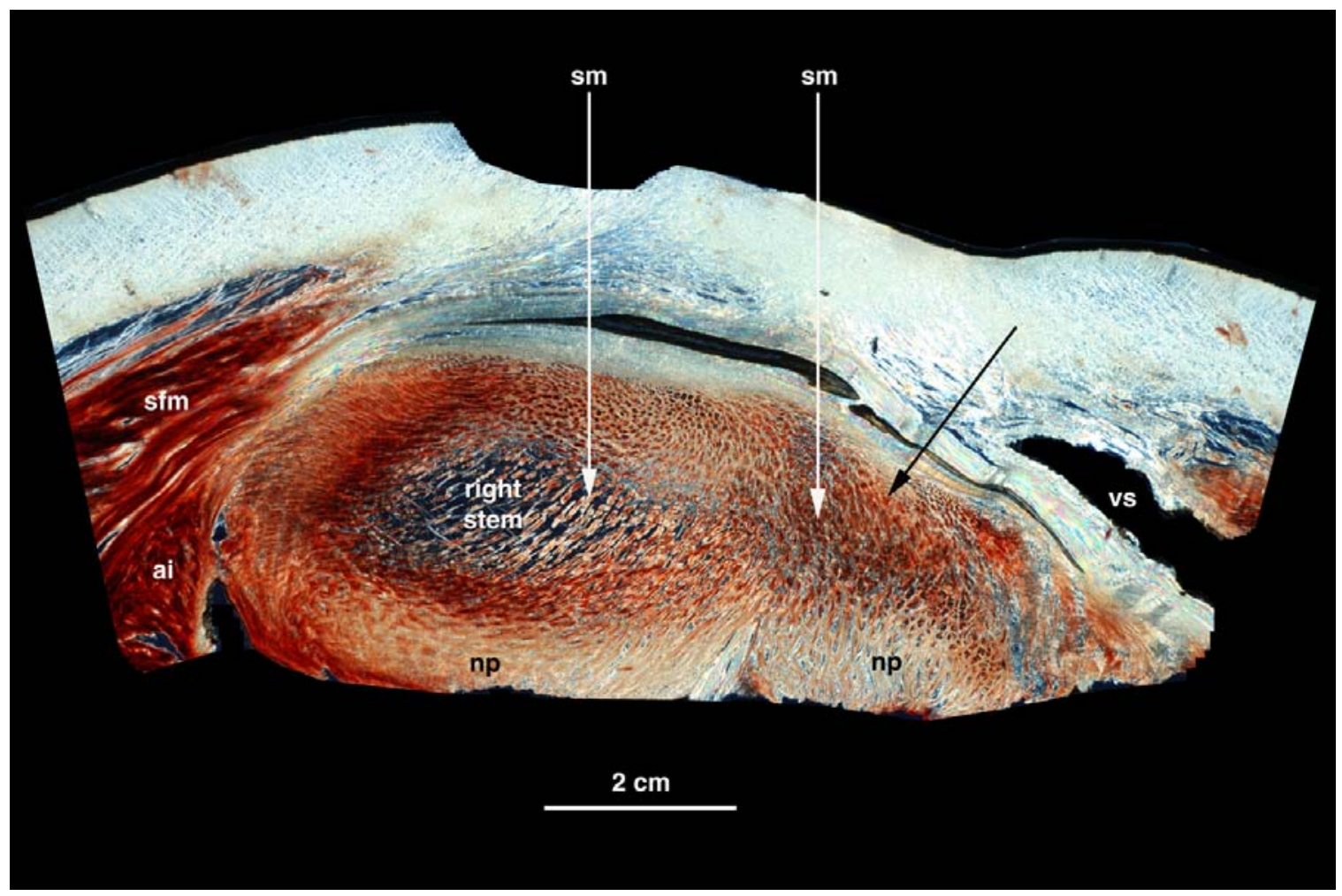

Fig. 9. Polarized light image of transverse section of the Tursiops truncatus caudal melon. This section demonstrates that the left branch ends blindly in a mass of muscle. This section is taken just rostral to the left anterior dorsal bursa. The black arrow points to the region where the left branch ends blindly in muscle and connective tissue, just rostral to the left anterior dorsal bursa. Rostral surface is facing the reader. ai, pars anterointernus; np, nasal plug; sfm, superficial facial muscle; sm, suspended nasal plug muscle; vs, vestibular sac. 


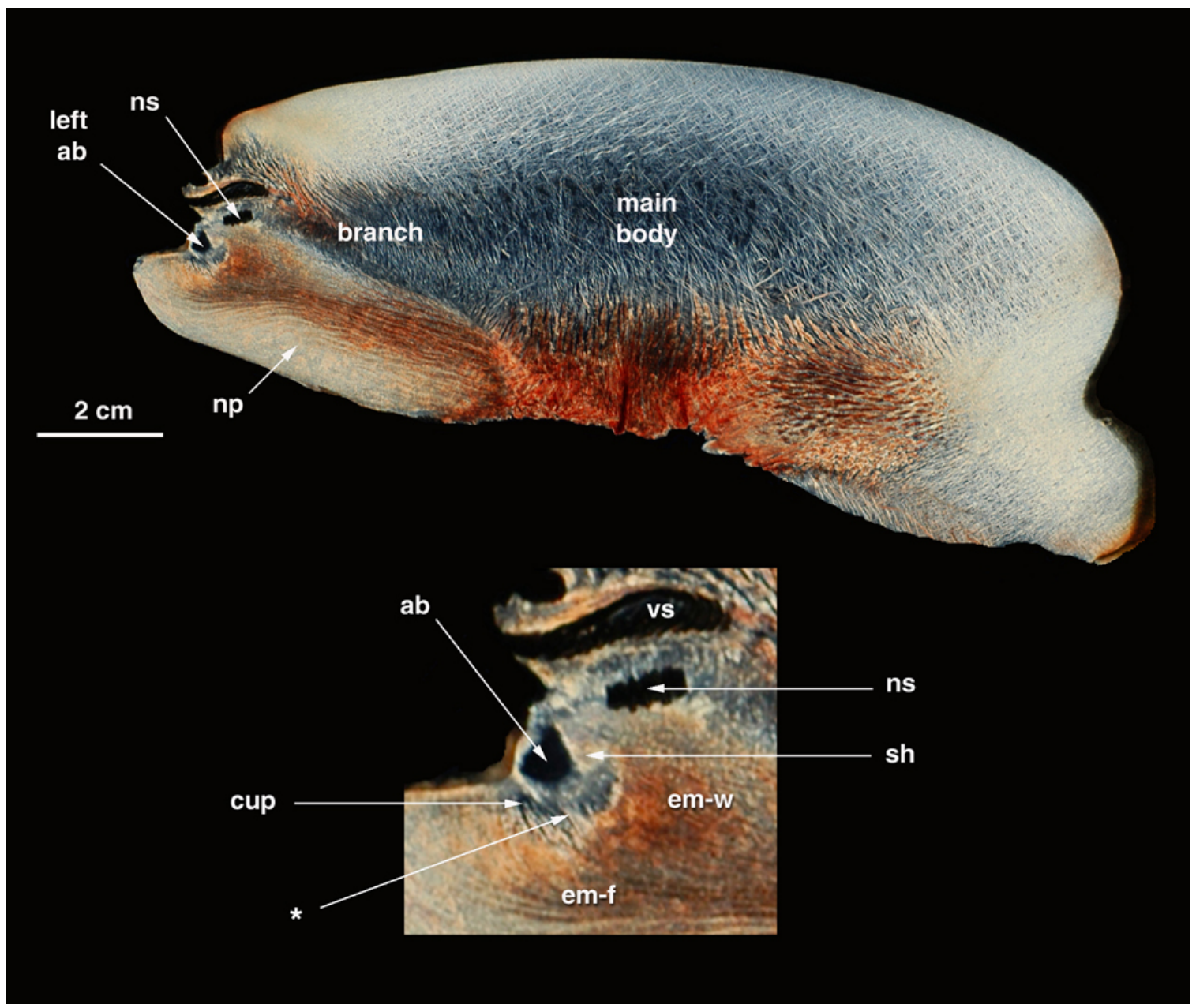

Fig. 10. Polarized light image of a sagittal section through the Tursiops truncatus melon, highlighting the left cup of the left caudal melon. This section is taken to the left of the blowhole. Rostral is to the right. ab, anterior dorsal bursa; asterisk $\left(^{*}\right)$, tendons of the embedded muscle of the left ventral floor and left lateral walls of the nasal plug; em-f, embedded muscle of the ventral floor of the nasal plug; em-w, embedded muscle of the left lateral wall of the nasal plug; np, nasal plug; ns, nasofrontal sac; sh, bursal connective tissue sheath; vs, vestibular sac. Inset: close up of the left anterior dorsal bursa and the embedded nasal plug muscle inserting into the left bursal connective tissue sheath. 
continuous tube of fat that connects the right anterior dorsal bursa to the main body of the melon. The left anterior dorsal bursa, however, is not directly connected to the main body of the melon through a fatty pathway. Instead, the connective tissue of the nasal plug and the nasal plug muscle lie between the left sound generator and the main body of the melon.

The Dermal Tissue Surrounding the Melon

The main body of the melon and the caudal melon are surrounded dorsolaterally by dense, fibrous connective tissue (Figs. 5, 6, 7). The serial sections and the polarized light images from these samples suggest that this dense connective tissue is blubber, as it lies deep to the epidermis and reticular dermis and is continuous with the blubber surrounding the body. The polarized light images from all three orthogonal body planes reveal that this tissue contains highly organized collagen fibers characteristic of structural blubber (e.g. Hamilton et al., 2004).

Facial Muscles that Act Upon the Main Body of the Melon

The ventral floor and ventrolateral walls of the main body of the melon are formed by bilaterally symmetrical rostral muscles. Mead (1975) described these muscles in two portions the lateral portion and the medial portion. The present study will describe the morphology of these muscles in more detail, introduce their tendinous connections to the melon, and describe a third portion of the rostral muscles, not previously identified, which will be termed the oblique rostral muscle.

The lateral rostral muscle, the most laterally placed of all of the rostral muscles, is an elongated muscle that forms the lateral walls of the main body of the melon (Figs. 11, 12). This muscle begins just rostral to the apex of the melon and extends to the level of the supraorbital 


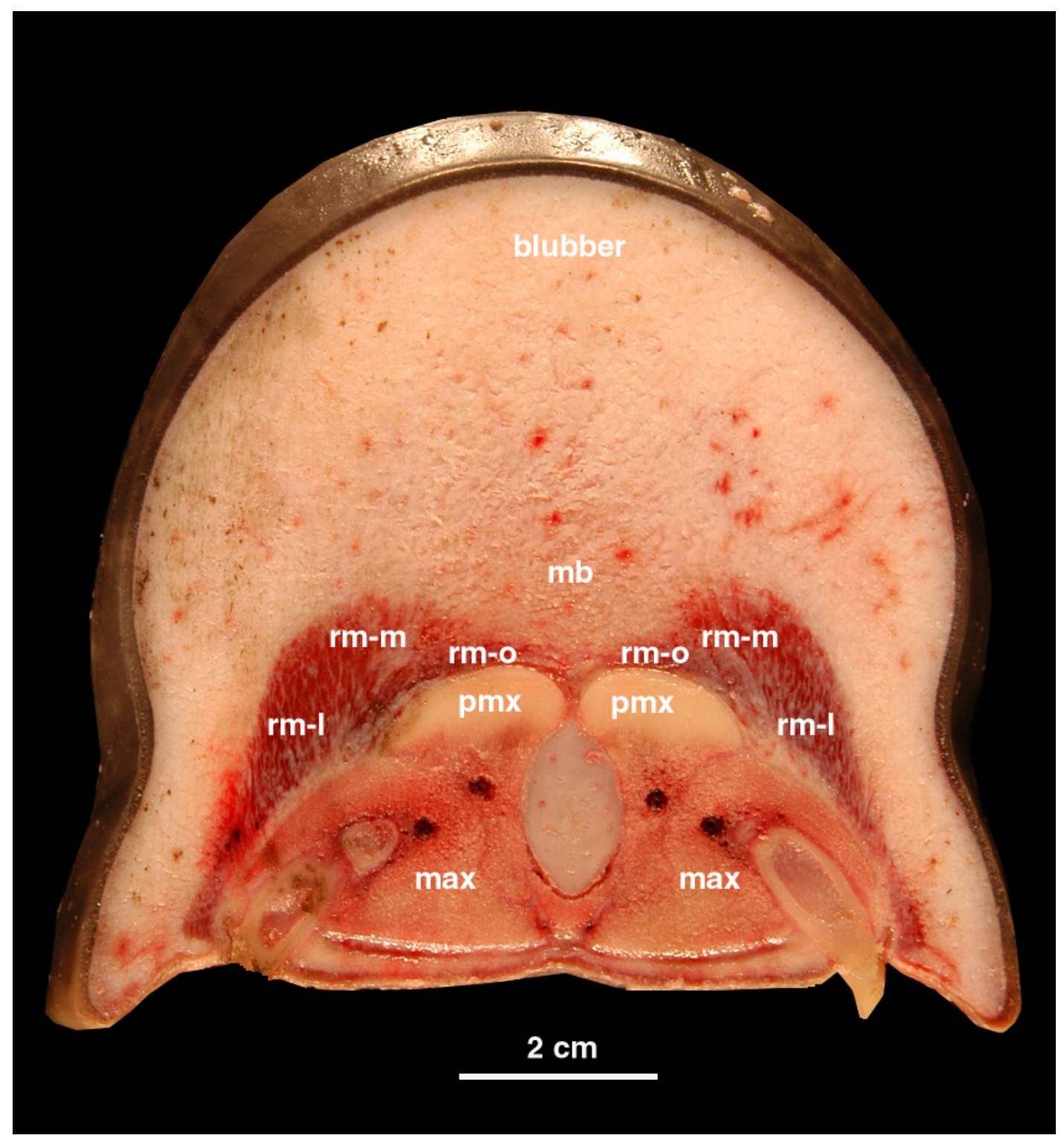

Fig. 11. Transverse section through the rostral end of the Tursiops truncatus melon, a few centimeters from the apex of the forehead. Rostral surface is facing the reader. mb, main body of the melon; mx, maxillae; pmx, premaxillae; rm-l, lateral rostral muscle; rm-m, medial rostral muscle; rm-o, oblique rostral muscle. 


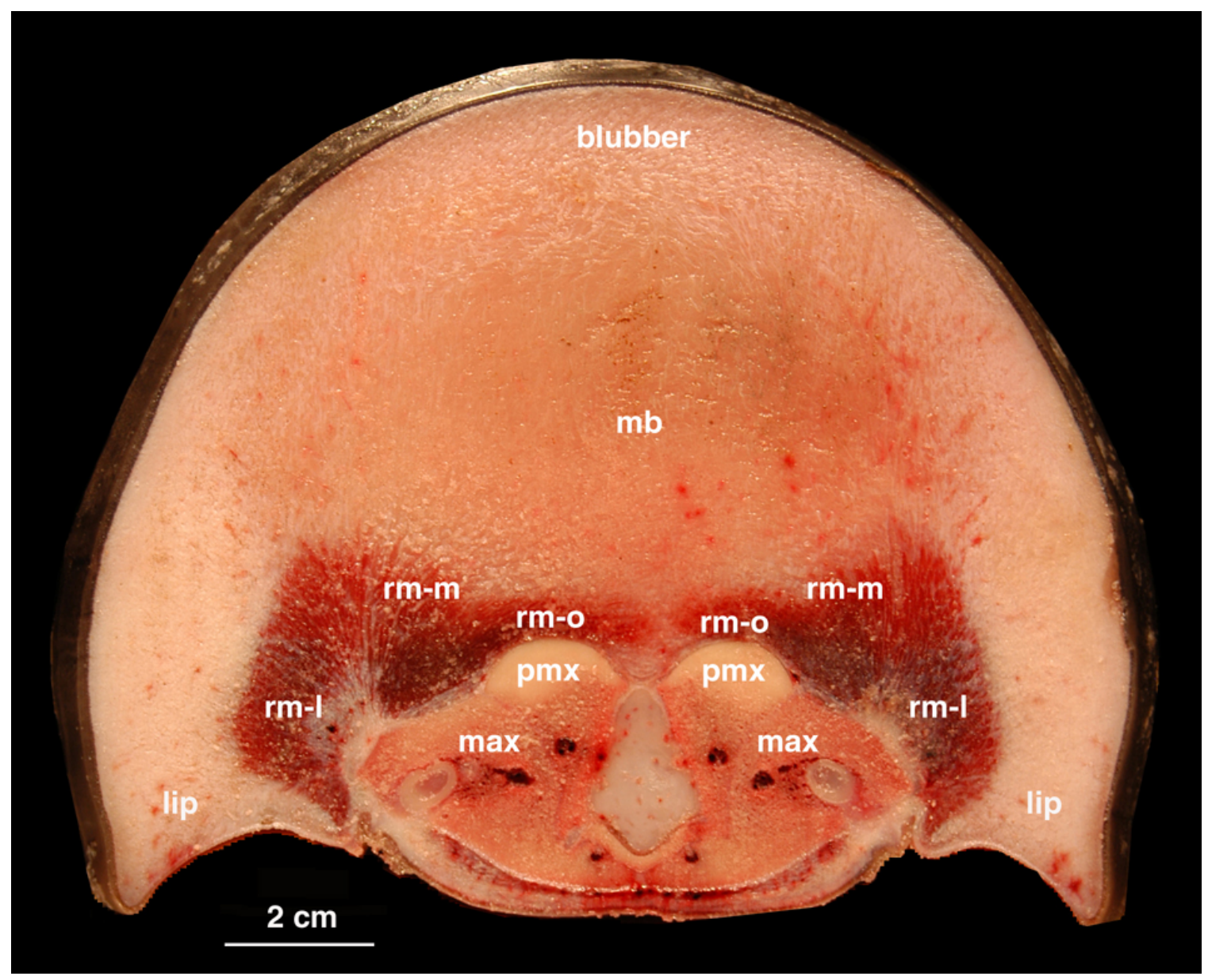

Fig. 12. Transverse section through the Tursiops truncatus melon, approximately $10 \mathrm{~cm}$ from the apex of the forehead. Rostral surface is facing the reader. mb, main body of the melon; mx, maxillae; pmx, premaxillae; rm-l, lateral rostral muscle; rm-m, medial rostral muscle; rm-o, oblique rostral muscle. 
notch (see Fig. 1). Caudally, the lateral rostral muscle continues as the superficial caudal facial muscles (pars posteroexternus, pars intermedius, pars anteroexternus, pars posterointernus, Mead, 1975) (Figs. 13, 14, 15). The fibers of the lateral rostral muscle originate from the maxillae, and lie almost completely within the transverse body plane. In cross-section, the lateral rostral muscles are fan-shaped (Figs. 11, 12). At its medial margin, the vertically oriented muscle fibers insert directly into the lateral edge of the body of the melon. Further laterally, the muscle fibers gradually decrease their angle and insert into the blubber that lies lateral to the melon and that forms the lip.

The lateral rostral muscles insert into the blubber through a highly organized tendon population (Fig. 16). The tendons of the vertically oriented muscle fibers traverse the lateral edge of the melon, and insert into the dorsolateral blubber that surrounds the melon. The lateralmost tendons insert directly into the lateral and ventral blubber of the lip and become woven into the collagen fiber matrix of the blubber. In contrast to the lateral rostral muscles, the superficial caudal facial muscles do not interact directly with the melon and will not be described further in this study (see Mead, 1975).

The medial rostral muscles are also an elongated muscle that lies just deep to the lateral rostral muscles (Figs. 11, 12). The medial rostral muscles define the ventrolateral walls of the main body of the melon. This muscle begins at the apex of the melon and continues caudally along the entire length of the main body of the melon. Rostrally, the medial rostral muscle is a laterally compressed, slender muscle, but it becomes increasingly broader along its caudal extent. The medial rostral muscle fibers originate from the dorsal surface of the maxillae and lie almost completely within the transverse body plane. In cross-section, the medial rostral muscles are 


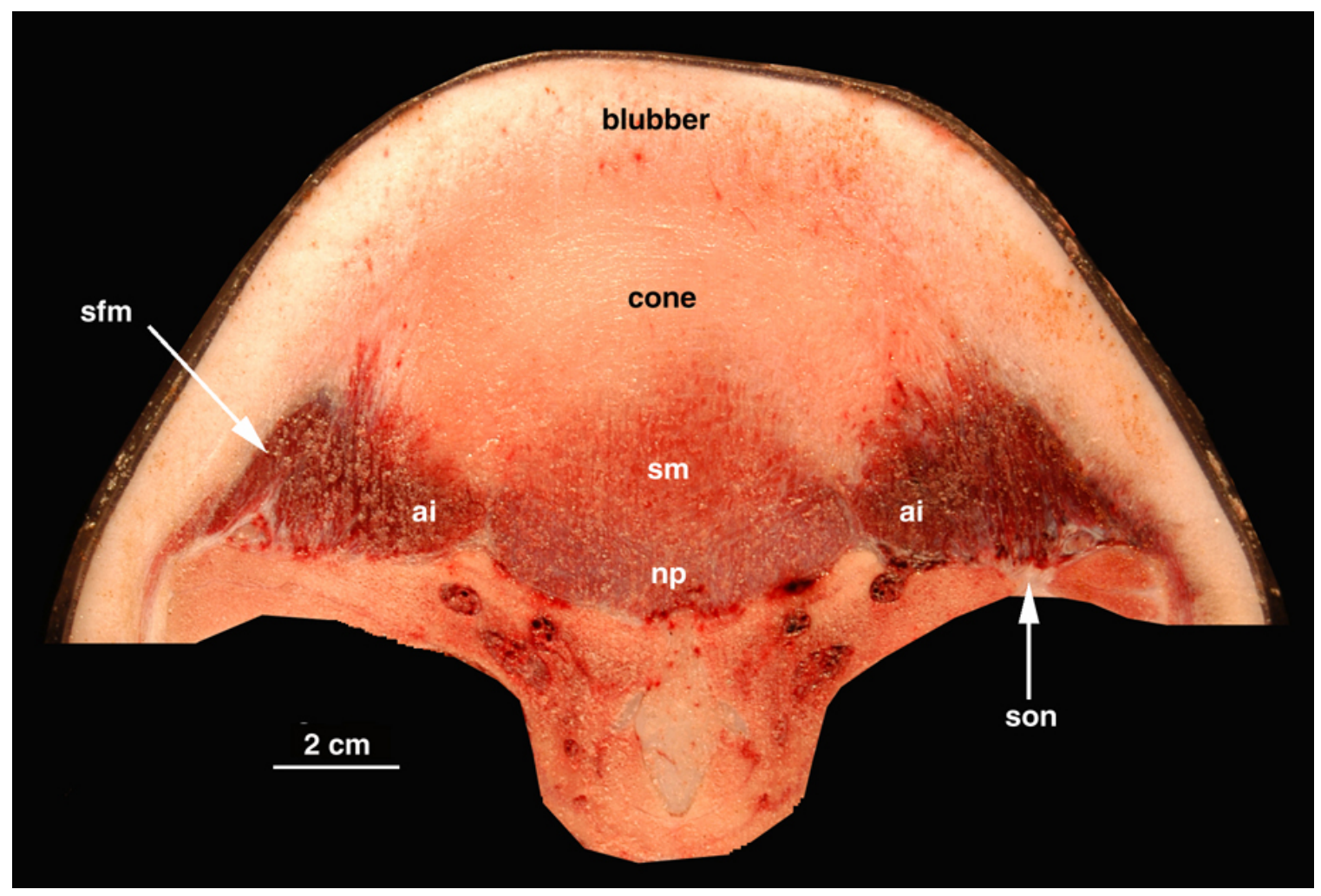

Fig. 13. Transverse section through the Tursiops truncatus melon, at the level of the supraorbital notch. Rostral surface is facing the reader. ai, pars anterointernus muscle; np, nasal plug; sfm, superficial caudal facial muscle; sm, suspended nasal plug muscle; son, supraorbital notch. The caudal extension of the oblique rostral muscle lies along the medial surface of the pars anterointernus muscle. 


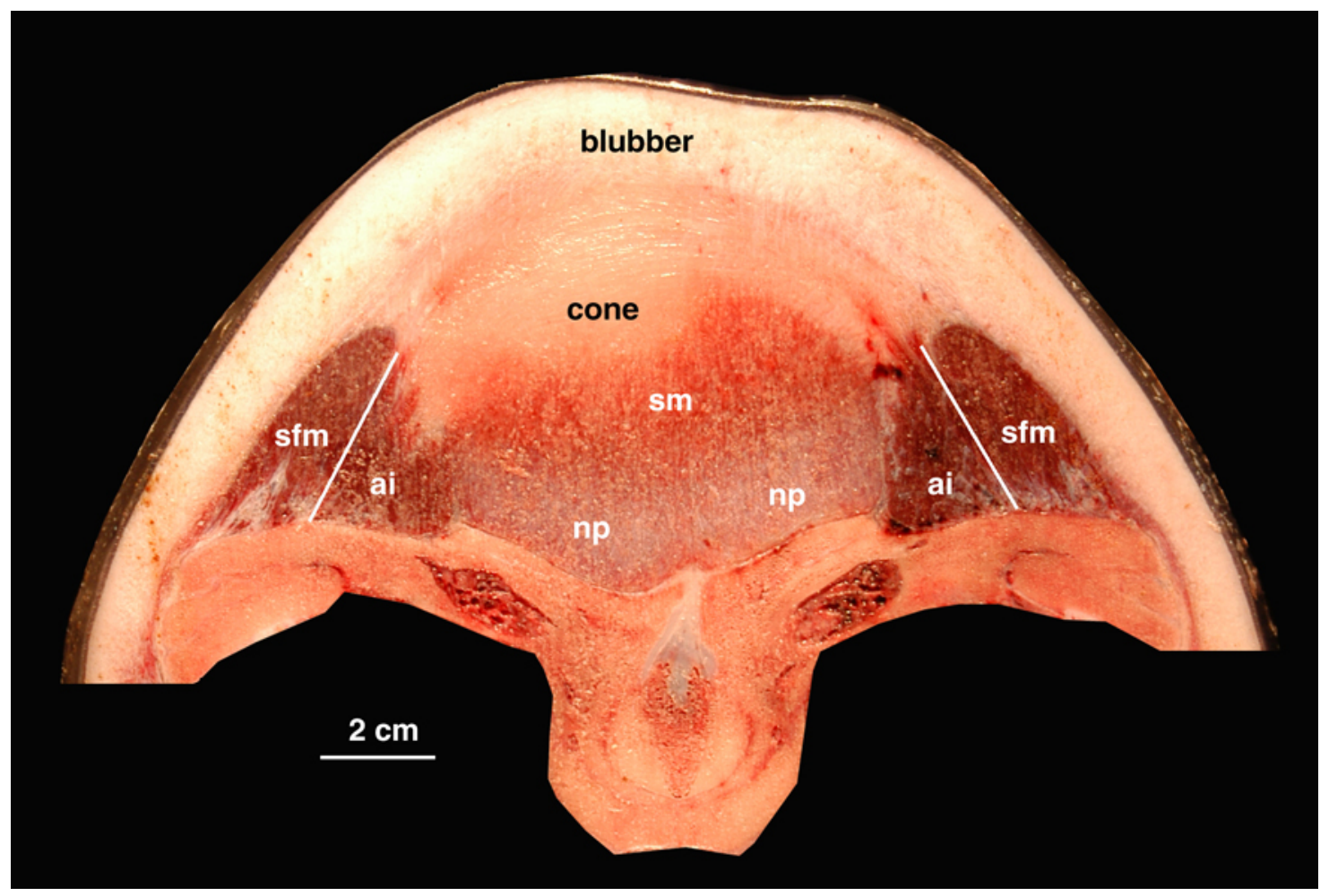

Fig. 14. Transverse section through the Tursiops truncatus melon, a few centimeters rostral to the blowhole. Rostral surface is facing the reader. ai, pars anterointernus muscle; np, nasal plug; sfm, superficial caudal facial muscle; sm, suspended nasal plug muscle. The caudal extension of the oblique rostral muscle lies along the medial surface of the pars anterointernus muscle. The solid white lines represent the fascial border between the pars anterointernus muscles and the superficial facial muscles. 


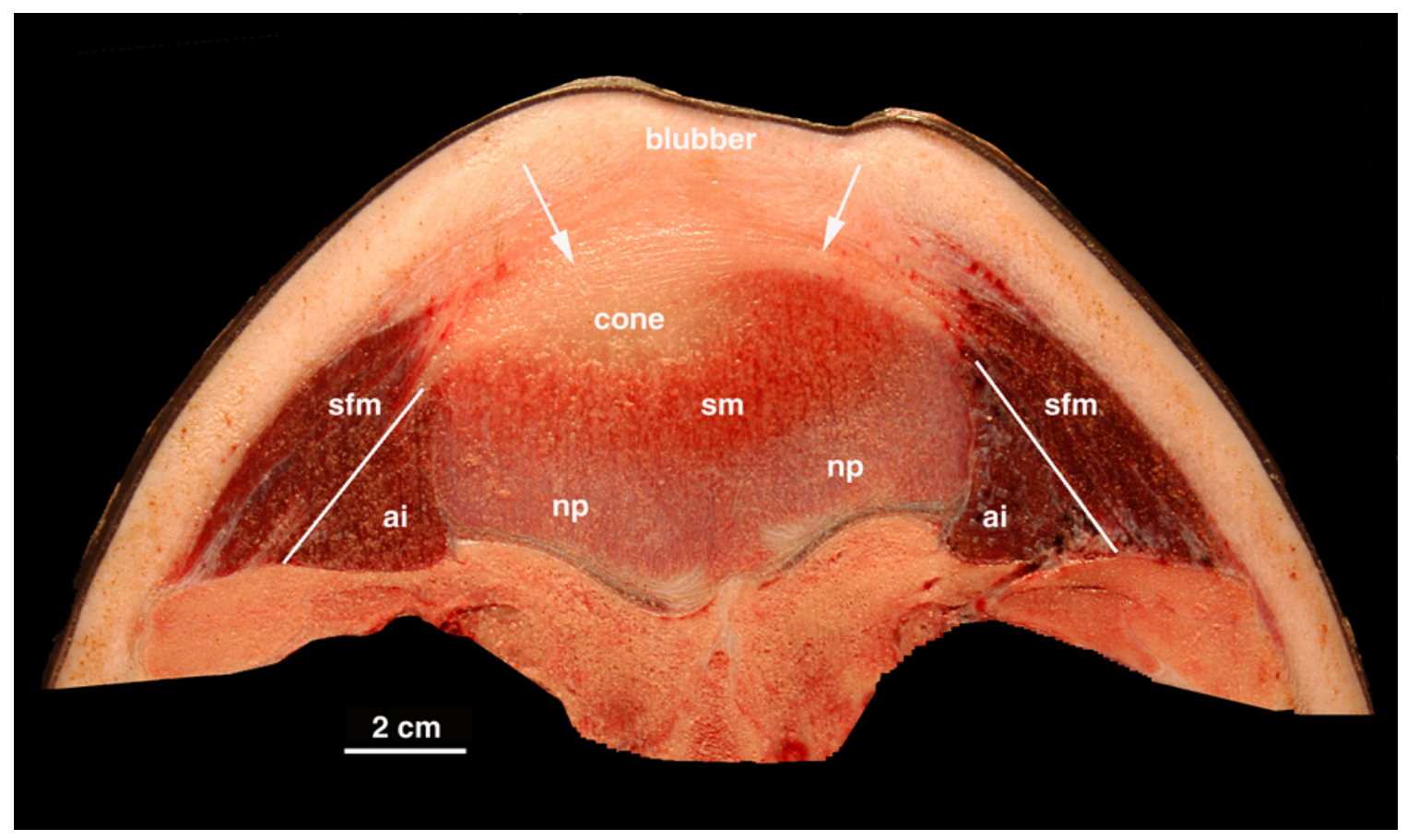

Fig. 15. Transverse section through the Tursiops truncatus melon, just rostral to the blowhole. Rostral surface is facing the reader. ai, pars anterointernus muscle; np, nasal plug; sfm, superficial caudal facial muscle; sm, suspended nasal plug muscle. The arrow points to the tendons of the pars anterointernus muscle. The caudal extension of the oblique rostral muscle lies along the medial surface of the pars anterointernus muscle. The solid white lines represent the fascial border between the pars anterointernus muscles and the superficial facial muscles. 


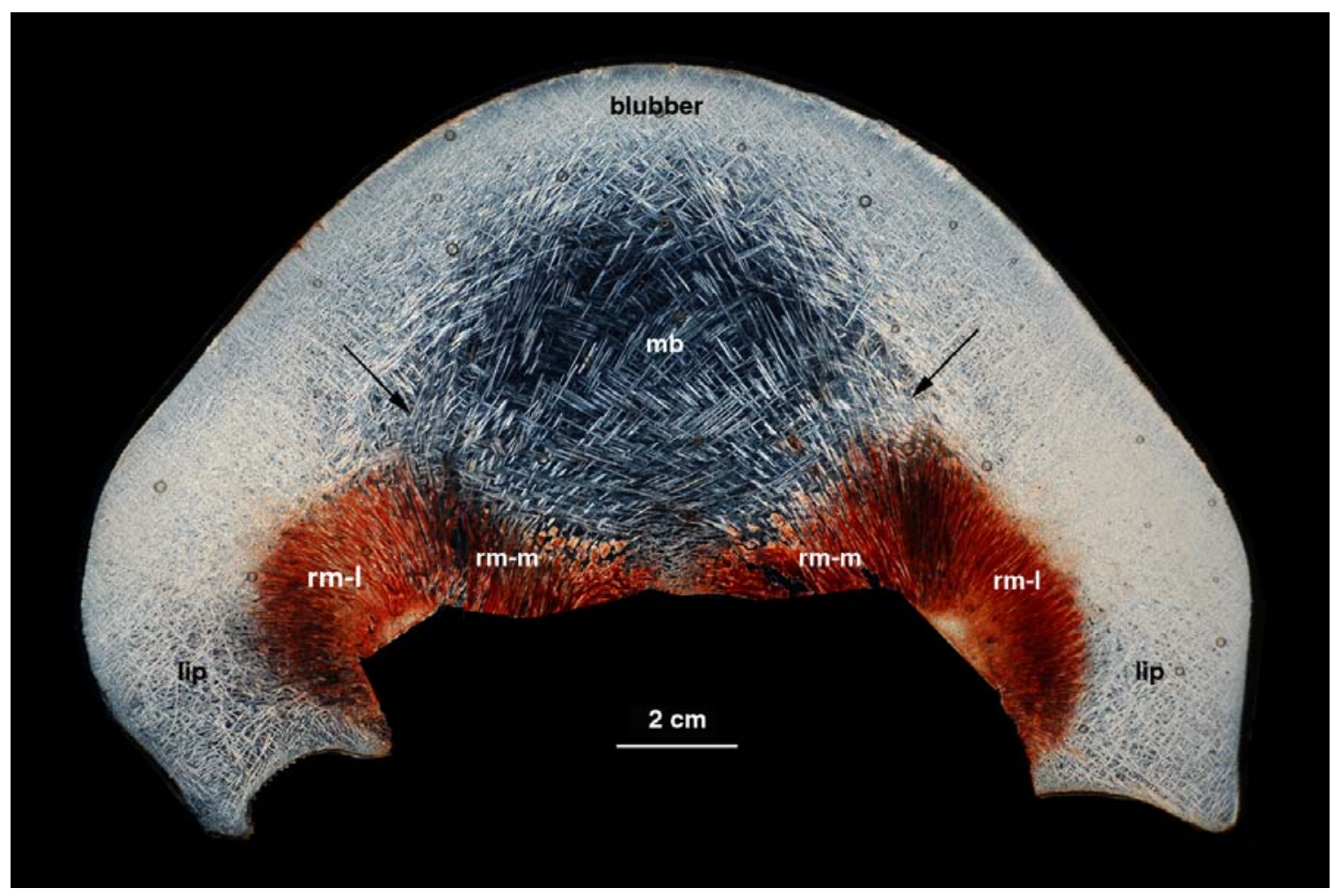

Fig. 16. Polarized light image of a transverse section through the Tursiops truncatus melon, at the origin of the nasal plug muscle. This section highlights the tendons of the lateral rostral muscle. Rostral surface is facing the reader. mb, main body of the melon; rm-l, lateral rostral muscle; rm-m, medial rostral muscle. Arrows point to the tendons of the lateral rostral muscles inserting in the lateral blubber surrounding the melon. 
also fan-shaped. The lateral most muscle fibers are vertically oriented and further medially they gradually decrease their angle (Figs. 11, 12).

The medial rostral muscle inserts into the melon through a highly organized tendon population, which mimics the fan-shaped morphology of this muscle (Fig. 17). The tendons arising from the vertical muscle fibers extend through the lateral edge of the melon and insert into the ipsilateral blubber surrounding the melon. As the muscle fibers gradually decrease their angle, their tendons traverse the melon and insert broadly across the dorsal and the contralateral blubber surrounding the melon. The tendons arising from the more horizontally oriented muscle fibers traverse the ventral portion of the melon and insert into the contralateral blubber.

There exists a third portion of the rostral muscles that, to date, has not been described. The oblique rostral muscle forms the ventral floor of the main body of the melon (Figs. 11, 12). The oblique rostral muscle originates on the premaxillae (Figs 11, 12, 18). Like the lateral and medial rostral muscles, the oblique rostral muscle is fan-shaped, except this muscle lies predominantly in the frontal body plane along the length of the main body of the melon. Because the bony rostrum lies at a low oblique angle relative to the frontal plane, the oblique rostral muscle arises serially from the surface of the premaxillae, like shingles off a sloping roof (Fig. 18). Within the frontal plane, these fibers run rostrally and medially, at oblique angles ranging from 45-60 degrees (Fig. 19). The oblique rostral muscles act upon the main body of the melon through a highly organized tendon population (Figs. 19, 20). These tendons also exist predominantly in the frontal plane. They arise from the muscle fibers, traverse the floor of the melon, and insert directly into the surrounding rostral and contralateral blubber surrounding the melon. Before these tendons insert into the contralateral blubber, they appear to weave through 


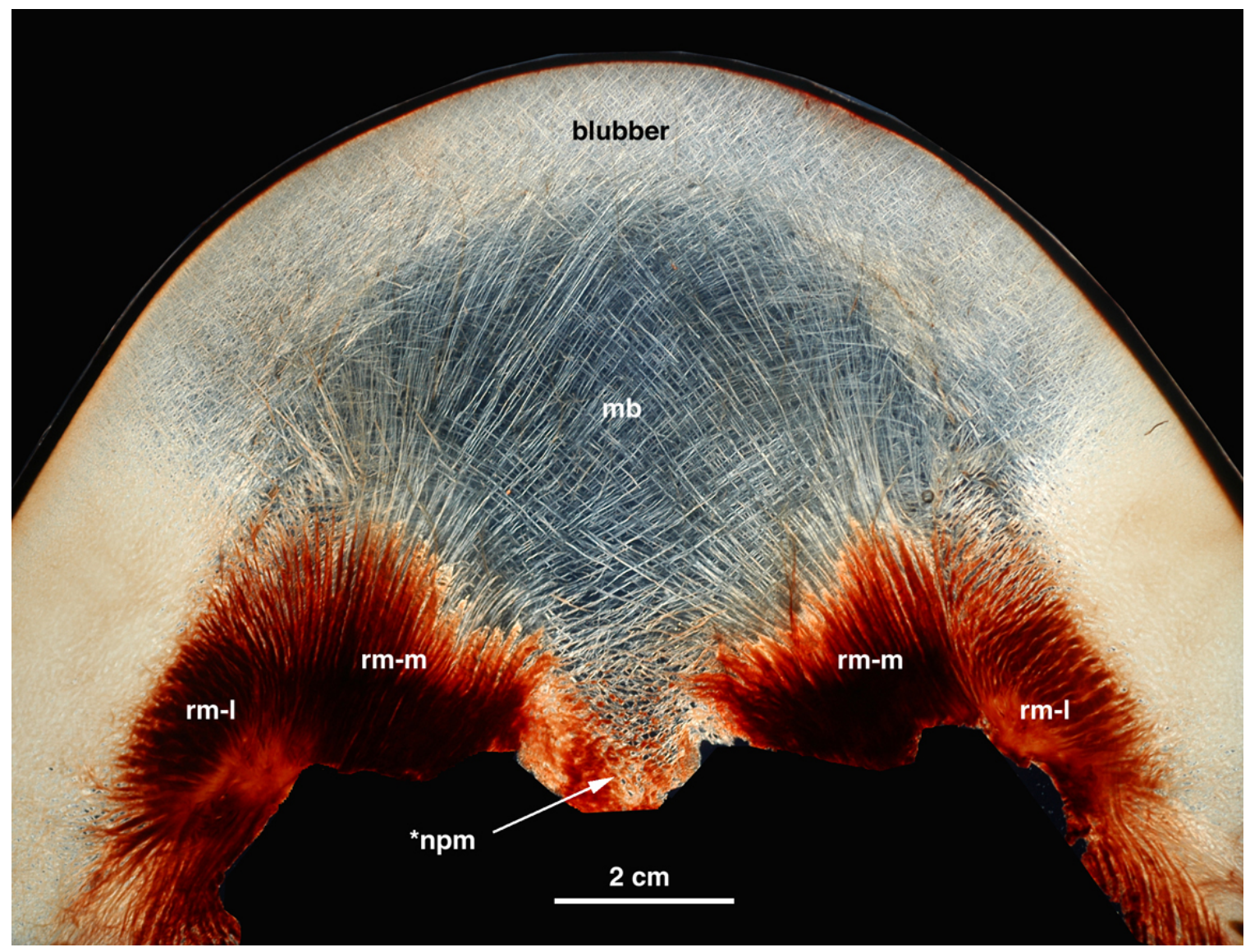

Fig. 17. Polarized light image of a transverse section through the Tursiops truncatus melon, at the origin of the nasal plug muscle. Rostral surface is facing the reader. mb, main body of the melon; rm-l, lateral rostral muscle; rm-m, medial rostral muscle; *npm, origin of the nasal plug muscle. 

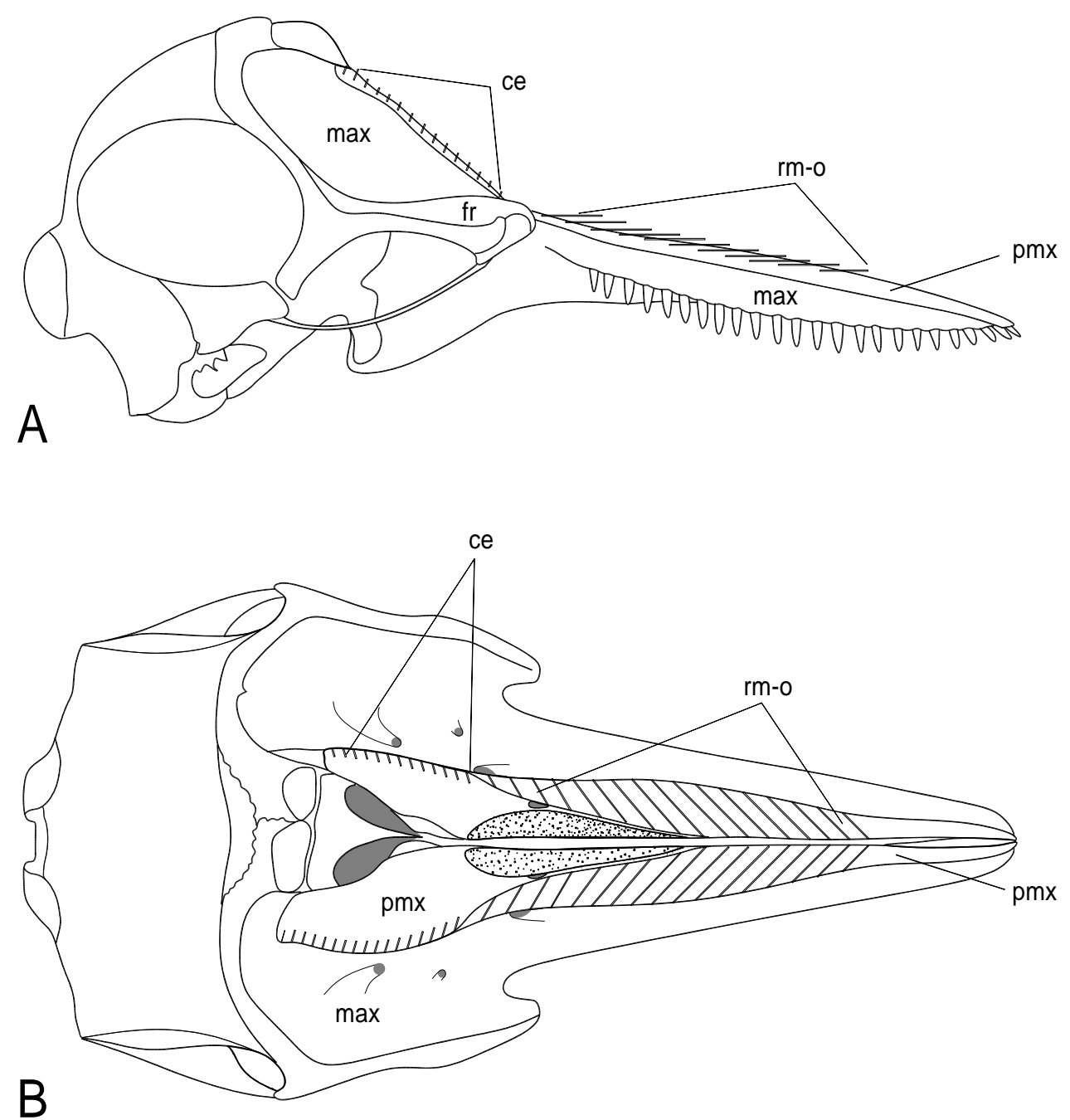

Fig. 18. Right lateral (A) and dorsal (B) view of a Tursiops truncatus skull illustrating the origin and orientation of the oblique rostral muscle (adapted from Rommel, 2006, p. 193). ce, caudal extension of the oblique rostral muscle, fr, frontal; max, maxillae; pmx, premaxillae; rm-o, oblique rostral muscle. The origin of the nasal plug muscle is stippled in the dorsal view (B) of the skull. 


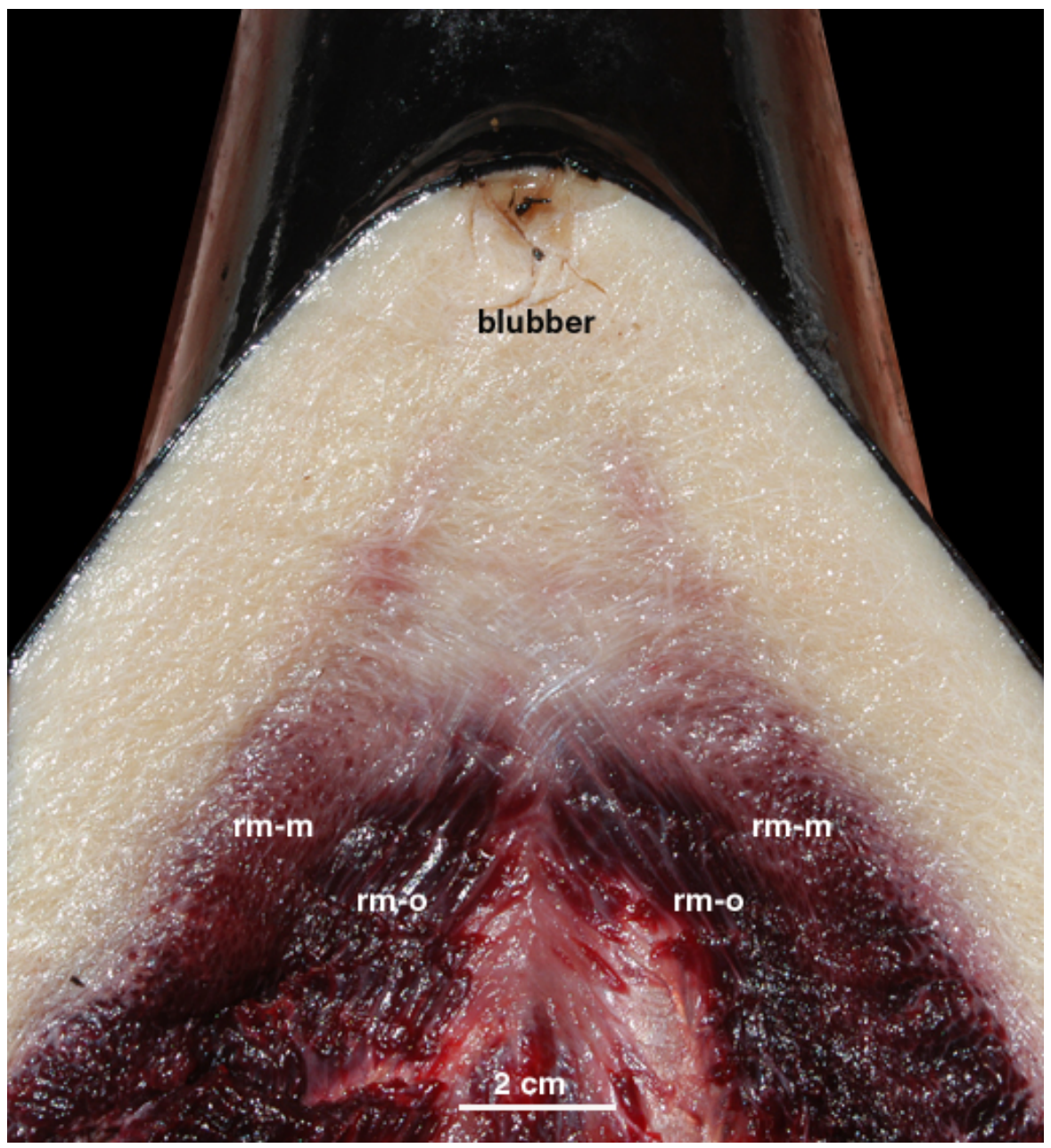

Fig. 19. Frontal section of the ventral portion of the main body of the melon of a Tursiops truncatus. Rostral is towards the top of the page. rm-m, medial rostral muscle; rm-o, oblique rostral muscle. 


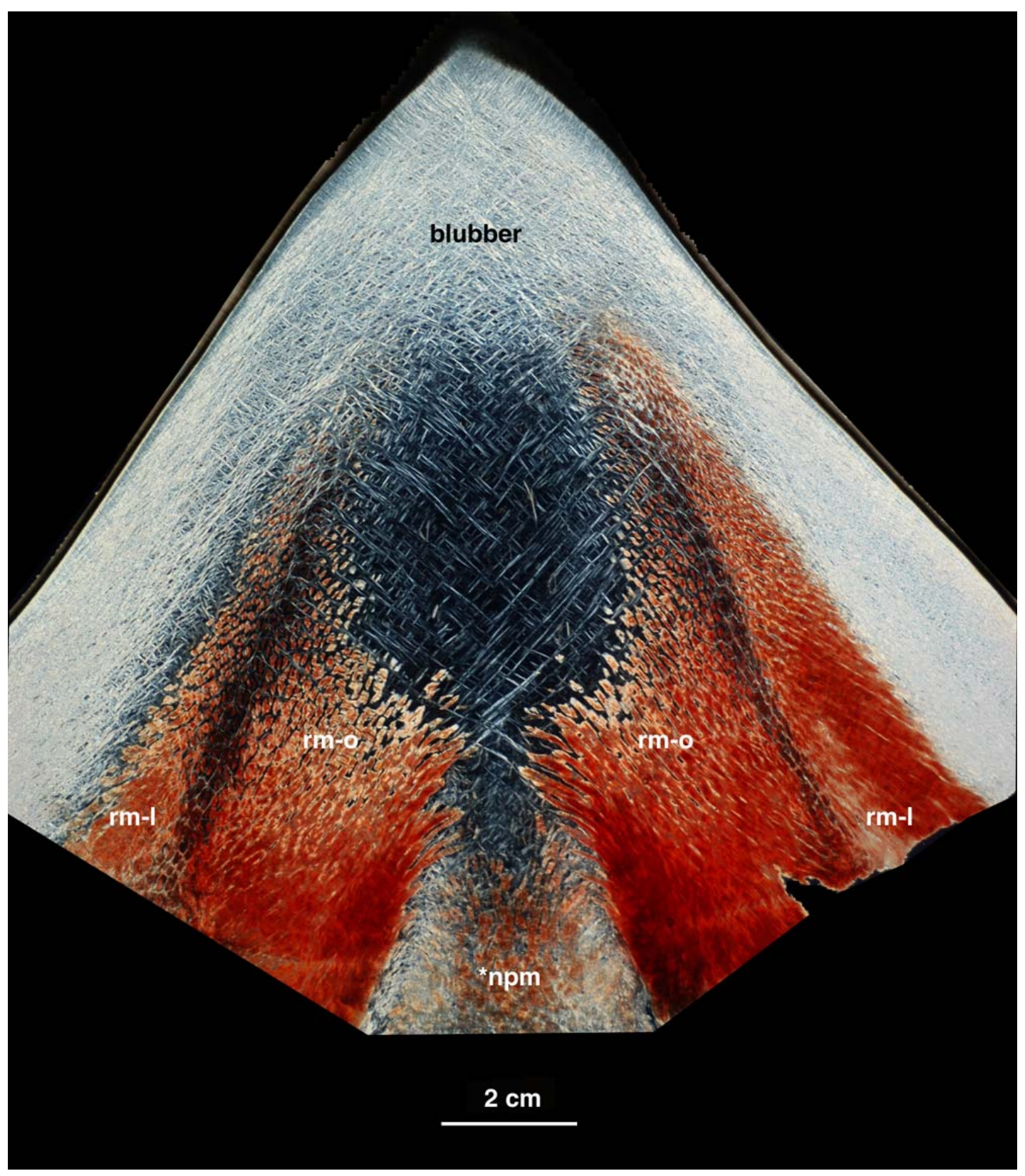

Fig. 20. Polarized light image of oblique frontal section through the ventral portion of the main body of the melon of a Tursiops truncatus. The tissue imaged above was sectioned parallel to the plane of the rostrum. Rostral is towards the top of the page. rm-l, lateral rostral muscle; rmo, oblique rostral muscle; *npm, origin of the nasal plug muscle. 
the medial rostral muscle fibers (Fig. 20). In summary, the floor of the main body of the melon is formed by the oblique rostral muscles and their tendons.

All three portions of the rostral muscles act upon the main body of the melon. The lateral and medial rostral muscles and their tendons lie predominantly in the transverse body plane. Contraction of these muscles would tense the surrounding blubber and change the height and width of the melon. The oblique rostral muscle lies predominantly within the frontal body plane, and its highly organized tendon population traverses the floor of the melon and inserts directly into the surrounding blubber. Contraction of this muscle may act to change the length of the main body of the melon.

Facial Muscles that Act Upon the Cone of the Caudal Melon

The caudal extensions of both the medial rostral muscle and the oblique rostral muscle act upon the caudal melon. The pars anterointernus muscle, the caudal extension of the medial rostral muscle, begins at the level of the supraorbital process (Mead, 1975) (Figs. 13, 14, 15). This muscle originates from the caudal ascending processes of the maxillae and lies lateral to the internal bony nares. The pars anterointernus muscle arises broadly from its origin on the maxilla, and its muscle fibers are directed medially towards the nasal passages (Figs. 13, 14, 15). The tendons of the pars anterointernus muscle form the dorsal roof of the cone of the caudal melon (Figs. 8, 15). Like the tendons of the medial rostral muscle, these tendons lie almost entirely within the transverse plane. The tendons arise from the anterointernus muscle, traverse the dorsal surface of the right cone and left branch of the caudal melon, and appear to join the tendons of the contralateral muscle. Contraction of the anterointernus muscle would create 
tension along its tendons and, thus, act to change the height of the right cone and left branch of the caudal melon.

The caudal extension of the oblique rostral muscle lies just medial to the pars anterointernus (Fig. 21). This muscle still originates from the premaxillae, but it is displaced to the extreme lateral edge of the premaxillae (Fig. 18). The premaxillae broaden laterally from the origin of the nasal plug muscle to the dorsal edge of the internal bony nares to accommodate the nasal plug muscle and the premaxillary nasal sacs. The caudal ends of the premaxillae curve dorsally, are almost vertically oriented and define the lateral edges of the bony internal nares. The oblique rostral muscle arises as a thin sheet of muscle off of the lateral edges of the premaxillae. Its fibers maintain their medio-rostral orientation, but at a much steeper oblique angle. Along the dorsal curvature of the premaxillae, these muscle fibers lie virtually horizontally within the frontal body plane.

As the oblique rostral muscle fibers vary their orientation along the premaxillae, so do their tendons (Fig. 21). This highly organized tendon population lies predominantly in the frontal body plane. These tendons arise from the oblique rostral muscles, traverse through the cone of the caudal melon, and join the tendons of the contralateral muscle. In the frontal plane, these tendons appear as a thick band of fibers that runs through the cone of the melon, reminiscent of a mitotic spindle in dividing cells (Fig. 21). The caudal oblique rostral muscle and its tendons follow the dorsal curvature of the premaxillae. Thus, the tendons form a band of connective tissue that curves dorsally and extends along the entire height of the cone, from the origin of the nasal plug muscle to the dorsal surface of the cone of the melon. Contraction of the oblique rostral muscles would produce tension along the tendons and may act to shorten the height and width of the cone. 


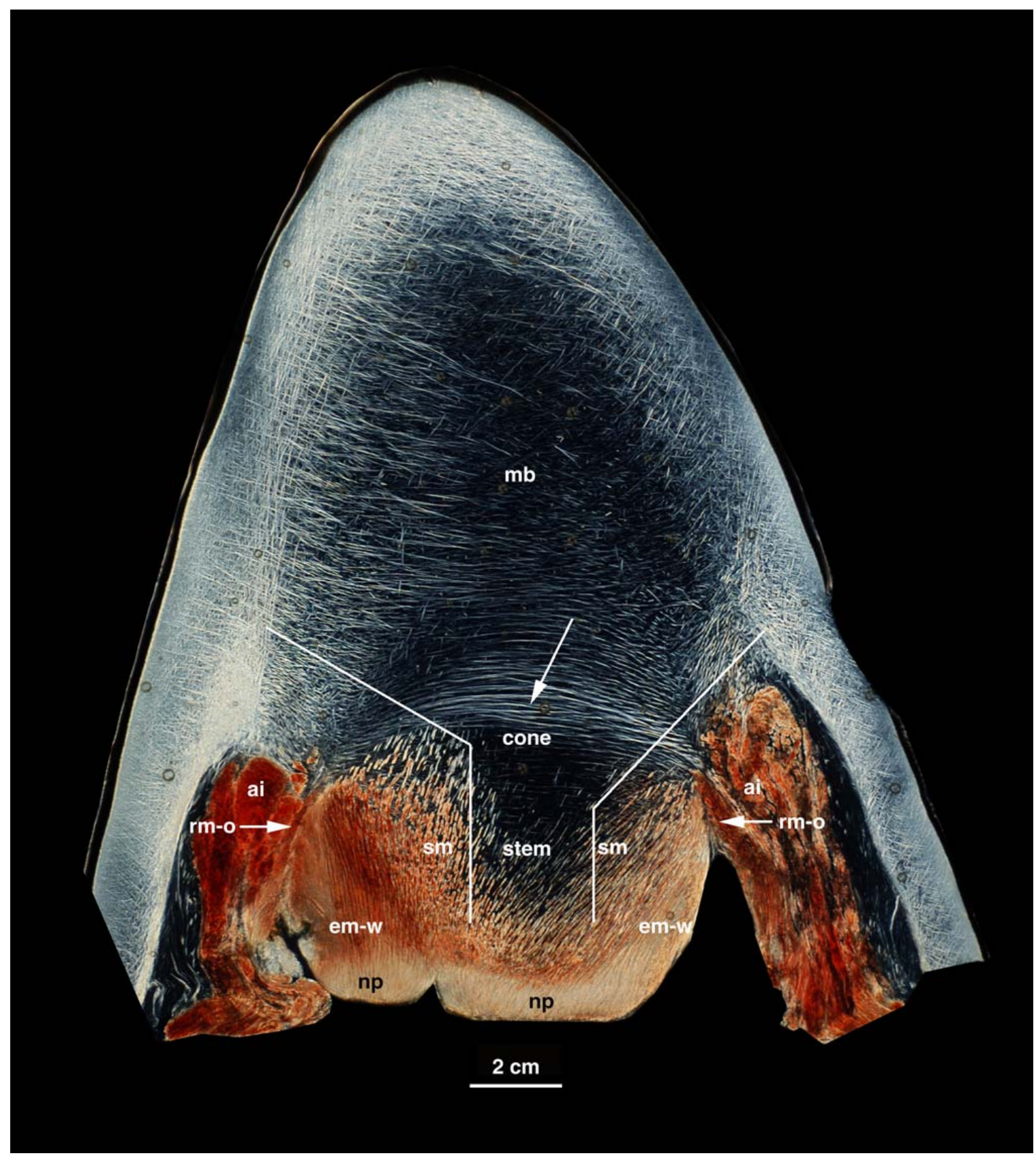

Fig. 21. Frontal section through the Tursiops truncatus melon, a few centimeters deep to the blowhole. Rostral is directed towards the top of the page. em-w, embedded muscle in the lateral walls of nasal plug; mb, main body of the melon; np, nasal plug; rm-o, oblique rostral muscle; sm, suspended nasal plug muscle. The arrow points to the tendons of the oblique rostral muscles. The white lines outline the lateral boundaries of the stem and cone of the melon. 
The Nasal Plug and the Caudal Melon

The caudal melon also lies within the boundaries of the nasal plug and is acted upon by the nasal plug muscle. The nasal plug and its associated muscle are complicated structures to visualize in three dimensions for a few important reasons. First, the nasal plug is an asymmetrical structure that varies in shape along its length. Second, the muscles that act upon the nasal plug lie within multiple body planes. Third, the nasal plug muscle is connected to both the nasal plug and to the caudal melon, each of which exhibits dramatic shape change along their respective lengths. The best way to visualize the relationship between these structures is to begin with a description of the nasal plug.

The nasal plug is shaped like a triangular cup, similar to the basket of a lacrosse stick (Fig. 22). The narrow apex of the cup is nestled ventrally and rostrally between the right and left premaxillae and the broad base is situated dorsocaudally, just ventral to the vertex of the skull. The nasal plug follows the dorsal curvature of the premaxillae and maxillae, and, thus, is angled obliquely and dorsally within the forehead. The cup-shaped nasal plug has a convex ventral floor which rests on the premaxillae and extends from the origin of the nasal plug muscle to the dorsolateral edges of the internal bony nares (Fig. 23).

The nasal plug also has short lateral walls (Figs. 21, 22). The lateral walls of the nasal plug gradually increase in height along their length, and become thickened bundles of connective tissue that extend slightly above the ventral floor, making the cup shape of the nasal plug more pronounced. At its dorsocaudal margin, the nasal plug also has a narrow arm of connective tissue that turns rostrally and forms a short dorsal "roof” (Figs. 22, 23). This connective tissue roof is present on the right and left side. On both sides, it lies rostral to the anterior dorsal bursa and just ventral to the nasofrontal sac. In summary, the nasal plug, which rests on the dorsal 


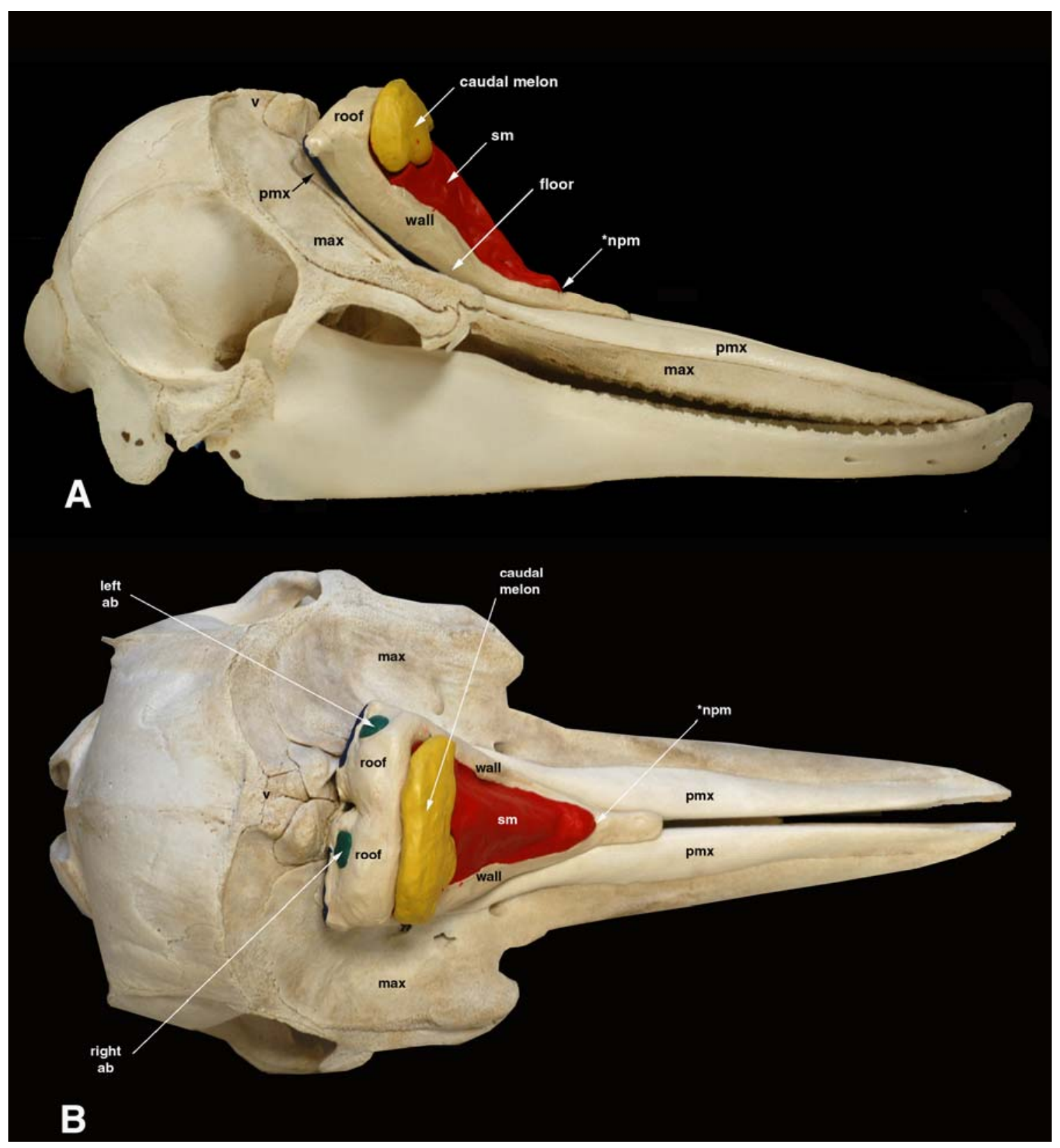

Fig. 22. Right lateral (A) and dorsal (B) view of a clay model of the nasal plug and associated muscle and connective tissue. Rostral is to the right. ab, anterior dorsal bursa; max, maxillae; pmx, premaxillae; sm, suspended nasal plug muscle; *npm, origin of the nasal plug muscle; v, vertex. The yellow clay represents the dorsocaudal portion of the melon. The embedded nasal plug muscle lies within the connective tissue of the nasal plug and is therefore represented by the beige clay. 


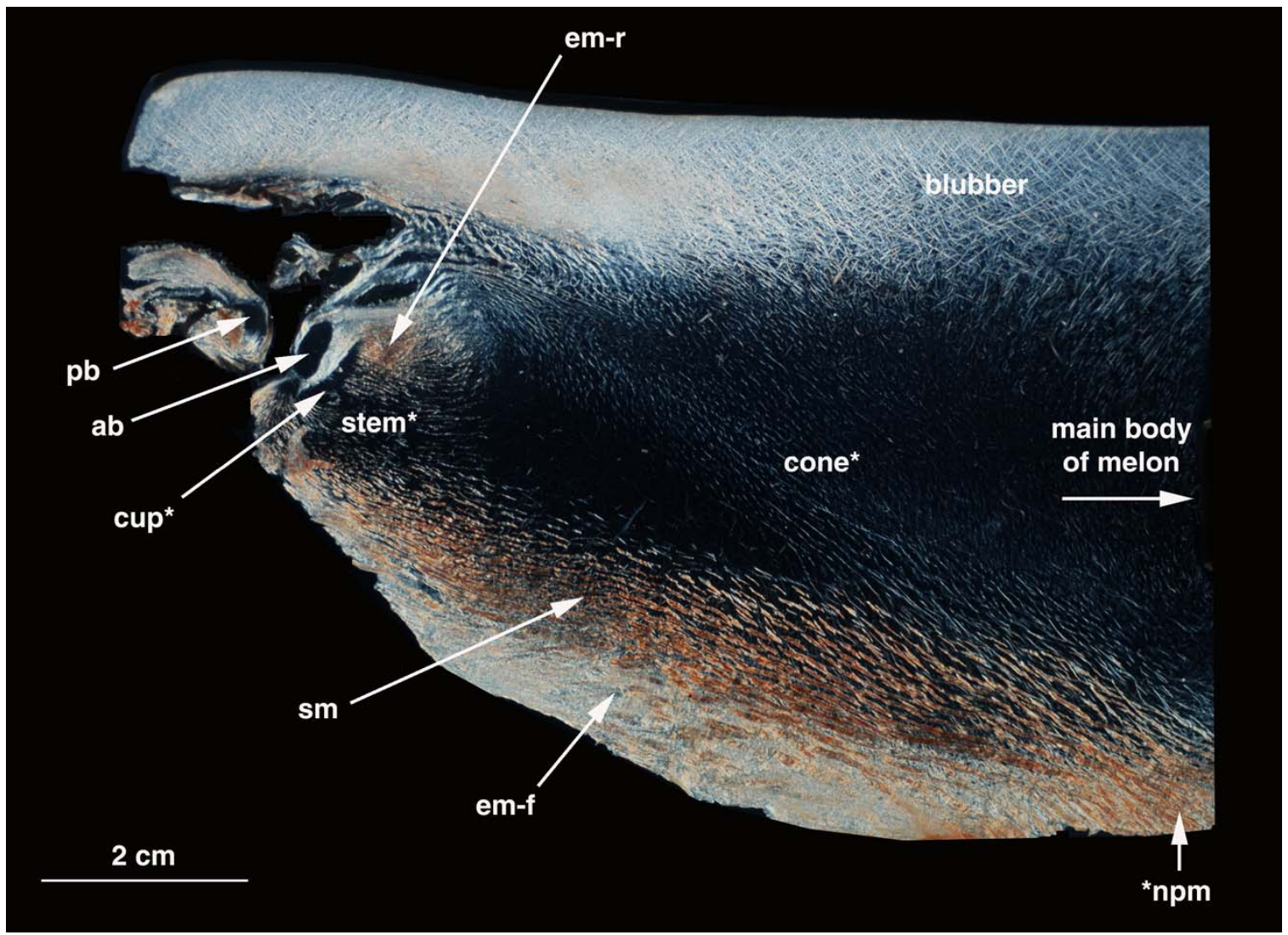

Fig. 23. Polarized light image of a sagittal section through the caudal end of the Tursiops truncatus melon, highlighting the floor and dorsal roof of the nasal plug. This section is taken to the right of the blowhole. Rostral is to the right. ab, anterior dorsal bursa; em-f, embedded muscle of the ventral floor of the nasal plug; em-r, embedded muscle of the roof of the nasal plug; pb, posterior dorsal bursa; sm, suspended nasal plug muscle; *npm, origin of the nasal plug muscle. The asterisks $(*)$ of the cup, stem, and cone indicate that these are the three regions of the right caudal melon. 
surface of the premaxillae, forms a concave container with a convex floor, and short lateral walls and a dorsal roof.

The right caudal melon lies within the concave container of the nasal plug (Fig. 23). The cone of the right caudal melon runs from the origin of the nasal plug muscle to the rostral edge of the roof, and lies on the ventral floor of the nasal plug along its entire length. The rostral edge of the roof defines the boundary between the cone and the stem of the melon. The narrow stem of the melon is nestled within the ventral floor, lateral walls, and dorsal roof of the nasal plug. The cup of the melon also lies within the nasal plug, just caudal and ventral to the short dorsal roof.

The left caudal melon also lies within the concave container of the nasal plug, except it occupies a more lateral position. Along its entire length, the left branch occupies a dorsolateral position relative to the ventral floor of the nasal plug (Fig. 8). At the caudal terminus of the branch, the roof and the left lateral wall of the nasal plug form a connective tissue "barrier" that separates the left branch from the left anterior dorsal bursa (Figs. 7, 9). Since the left cup is positioned in the lateral corner of the nasal plug, it is nestled between the ventral floor and the left lateral wall of the nasal plug (Fig 11).

The Caudal Melon, the Nasal Plug, and the Nasal Plug Muscle

The nasal plug and the caudal melon are each acted upon by the nasal plug muscle. There are two portions of the nasal plug muscle, which will be termed the "embedded muscle" and the "suspended muscle". Each portion will be described separately because they differ in muscle fiber orientation and in how they are connected to the caudal melon. The fundamental differences between these two portions of the nasal plug muscle is that the embedded muscle is 
completely contained within the connective tissue of the nasal plug and the suspended muscle fibers are suspended between the nasal plug and the caudal melon.

\section{Embedded Muscle}

The embedded muscle fibers are those that lie predominantly within the connective tissue matrix of the nasal plug (Figs. 7, 8, 10, 21, 22-25), i.e. they originate from and insert into the connective tissue of the nasal plug. Along the ventral floor, the muscle fibers are oriented parallel to the length of the nasal plug and are oriented predominantly within the sagittal body plane (Figs. 10, 23, 25). This muscle fiber population originates ventrorostrally, and inserts further caudally into the connective tissue of the nasal plug. These embedded muscle fibers are long, but do not appear to span the entire length of the floor of the nasal plug. The embedded muscle fibers within the floor may help to pull the fleshy nasal plugs rostrally and ventrally during a respiratory event. The embedded muscle in the floor lies ventral to the right and left caudal melon (Figs. 8, 10, 23). Thus, contraction of this muscle may also indirectly affect the shape of the caudal melon. When this muscle contracts to move the fleshy nasal plug, it may also cause the right and left caudal melon to shorten along their respective lengths.

On the left side of the nasal plug, the embedded muscles of the floor act directly on the bursal connective tissue sheath (Fig. 10). This muscle has a highly organized tendon population that traverses the ventral portion of the left cup, and inserts into the ventral surface of the left bursal connective tissue sheath. Contraction of this muscle would act upon the bursal connective tissue sheath.

Embedded muscle fibers also lie within the lateral walls of the nasal plug, and are oriented almost completely in the frontal body plane (Figs. 7, 10, 21, 22). On the right side of 


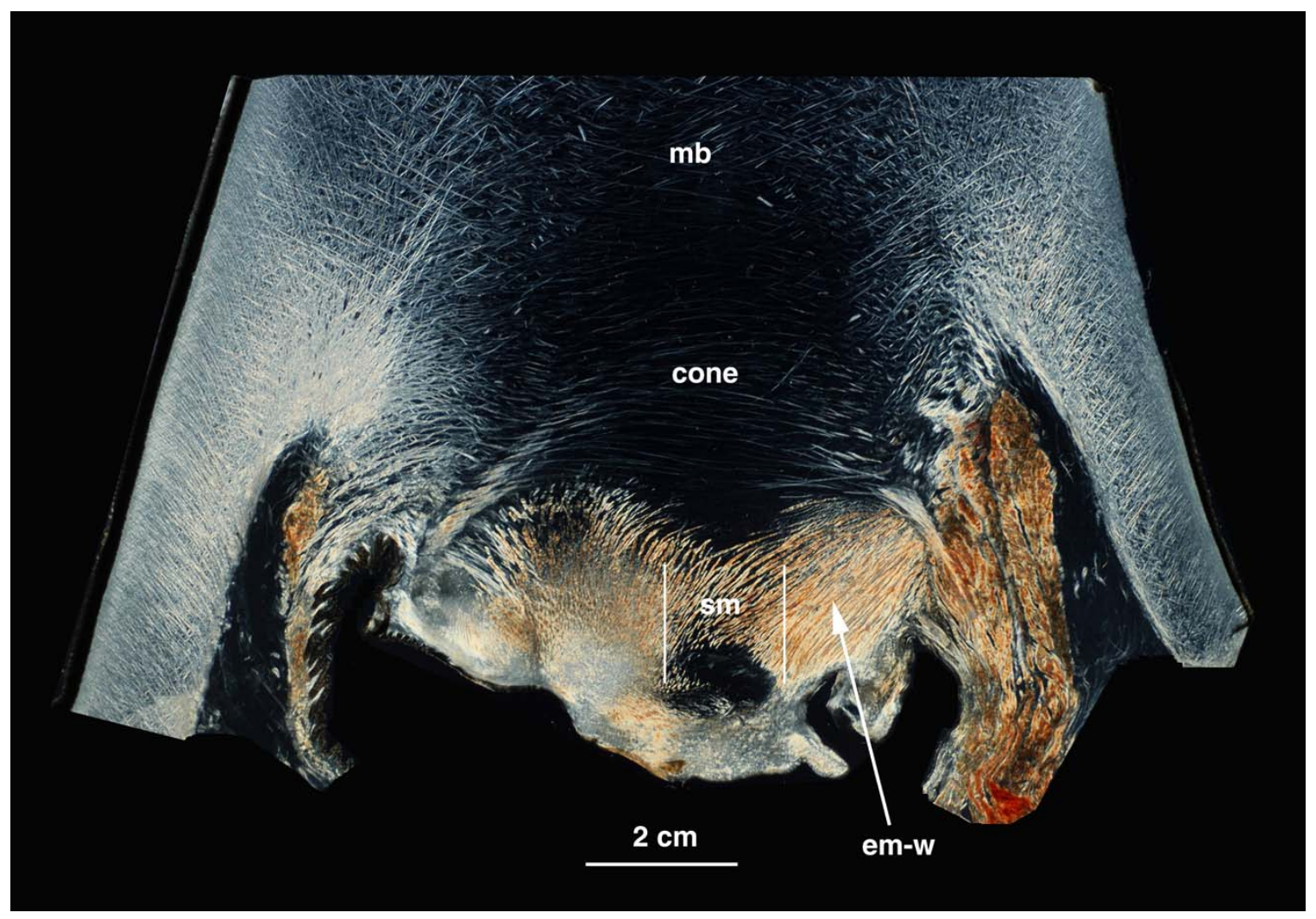

Fig. 24. Frontal section through the Tursiops truncatus melon, just ventral to the right dorsal bursa. Only the caudal half of the section is shown, and rostral is directed towards the top of the page. em-w, embedded muscle in the lateral walls of nasal plug; mb, main body of the melon; sm, suspended nasal plug muscle within the stem of the melon. The white lines delineate the lateral boundaries of the stem. 


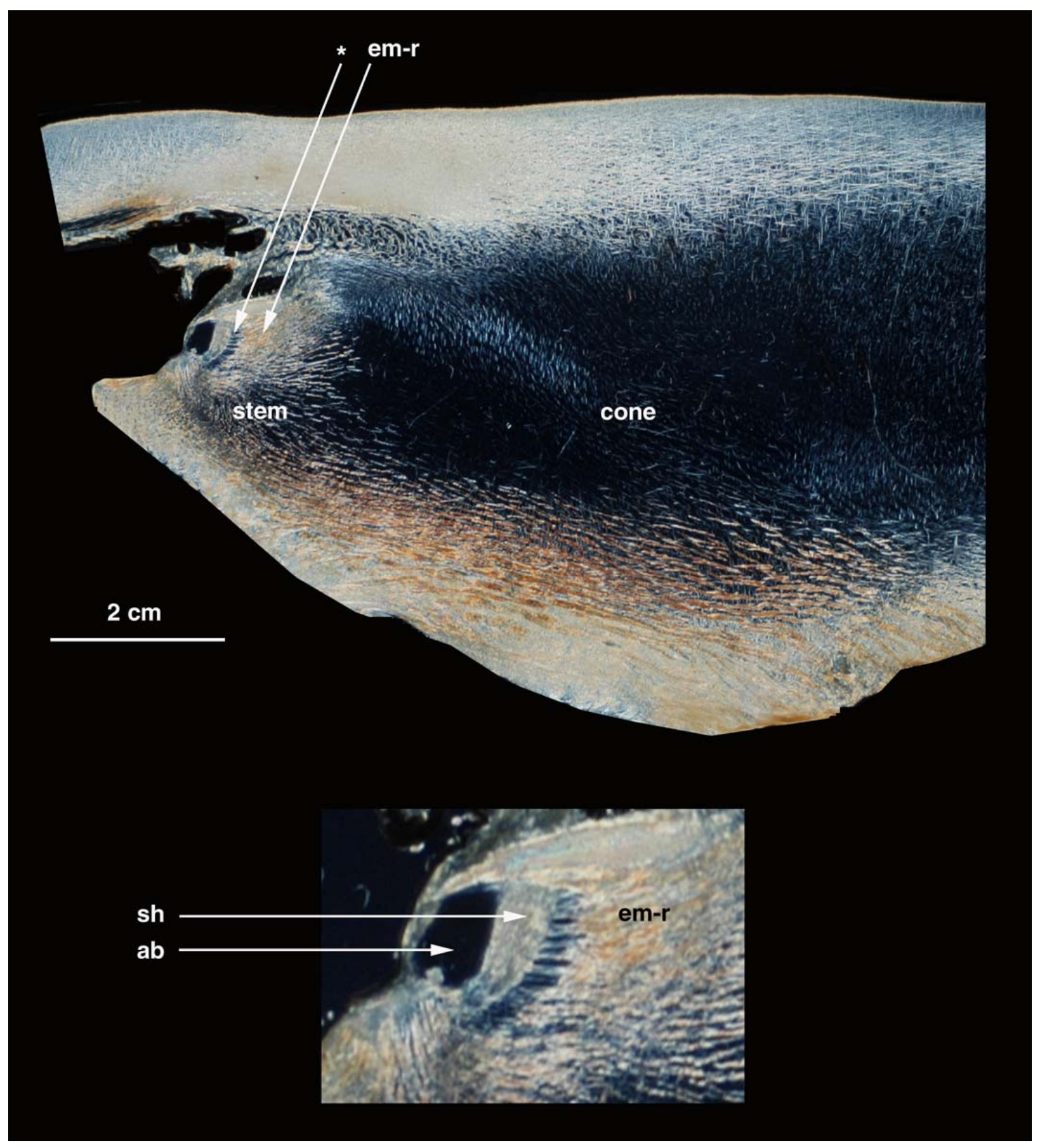

Fig. 25. Polarized light image of a sagittal section through the caudal end of the Tursiops truncatus melon, highlighting the tendons of the embedded muscles in the dorsal roof of the nasal plug. This section is taken to the right of the blowhole. Rostral is to the right. ab, right anterior dorsal bursa; em-r, embedded muscle of the roof of the nasal plug; sh, bursal connective tissue sheath; asterisk $(*)$, tendons of the embedded muscle. Inset: close up of the embedded muscle tendons inserting into the bursal connective tissue sheath. 
the nasal plug, the muscle fibers originate from the connective tissue on the rostrolateral surface of the nasal plug, and have two insertion points. Ventrally, these muscle fibers insert into the caudolateral surface of the nasal plug. More dorsally, these muscle fibers insert directly into the lateral wall of the right stem of the melon (Fig. 24). The embedded muscle fibers within the wall may function to pull the nasal plug rostrally and ventrally during respiration. Since these fibers are also directly connected to the right stem of the melon, contraction of this muscle may act to change its shape.

There is also embedded muscle in the left lateral wall of the nasal plug (Figs. 7, 10). The embedded muscle within the left lateral wall lies rostral and ventral to the left cup and left anterior dorsal bursa. Thus, the embedded muscle lies at the boundary between the left branch and the left anterior dorsal bursa and occludes the pathway between these two structures. The embedded muscle fibers in the left wall have a highly organized tendon population that traverses the rostral portion of the left cup and inserts directly into the rostral surface of the left bursal connective tissue sheath (Fig. 10). Contraction of this muscle would act upon the connective tissue sheath surrounding the left anterior dorsal bursa.

The short, dorsal roof of the nasal plug also contains embedded muscle fibers that lie within the frontal body plane. These embedded muscle fibers originate from the rostral end of the connective tissue roof and extend along the length of the roof (Figs. 23, 25). These embedded muscle fibers have a highly organized population of short, parallel tendons that traverses the right cup (Fig. 25) and inserts into the dense connective tissue sheath surrounding the right anterior dorsal bursa. Contraction of the embedded muscle in the roof of the nasal plug would act upon the right bursal connective tissue sheath. 
To summarize this complex morphology, the embedded muscle of the nasal plug is intimately connected to the right and left caudal melon. The embedded muscle in the lateral walls and the dorsal roof act upon the right stem and right bursal connective tissue sheath, respectively. In contrast, the muscle within the left lateral walls and the ventral floor traverses the cup and inserts into the left bursal connective tissue sheath. The embedded muscle of the left lateral wall also forms a barrier to occlude the connection between the left branch and the left anterior dorsal bursa.

\section{Suspended Muscle}

The suspended muscle lies within the concave container of the nasal plug (Fig. 22). This muscle originates from the connective tissue matrix of the nasal plug and its fibers are oriented at an oblique angle relative to the sagittal body plane (Fig. 23). The suspended muscle acts upon the right and left caudal melon, but its morphology is extremely asymmetrical in these two regions. The tendinous connection between the suspended muscle and the right cone and stem will be described first.

The tendons of the suspended muscle traverse the cone of the melon and insert further dorsally into the dorsocaudal region of the nasal plug. Like the muscle fibers, these tendons are oriented at a slight angle relative to the sagittal plane. Contraction of the suspended muscle could move the nasal plug rostroventrally, which would also change the length of the cone of the melon. The tendons of the suspended nasal plug muscle also traverse the right stem of the melon (Fig. 24) and insert into the ventral surface of the right bursal connective tissue sheath (Fig. 26). Contraction of this muscle could change the shape of the stem (see description below) and act upon the right bursal connective tissue sheath. 


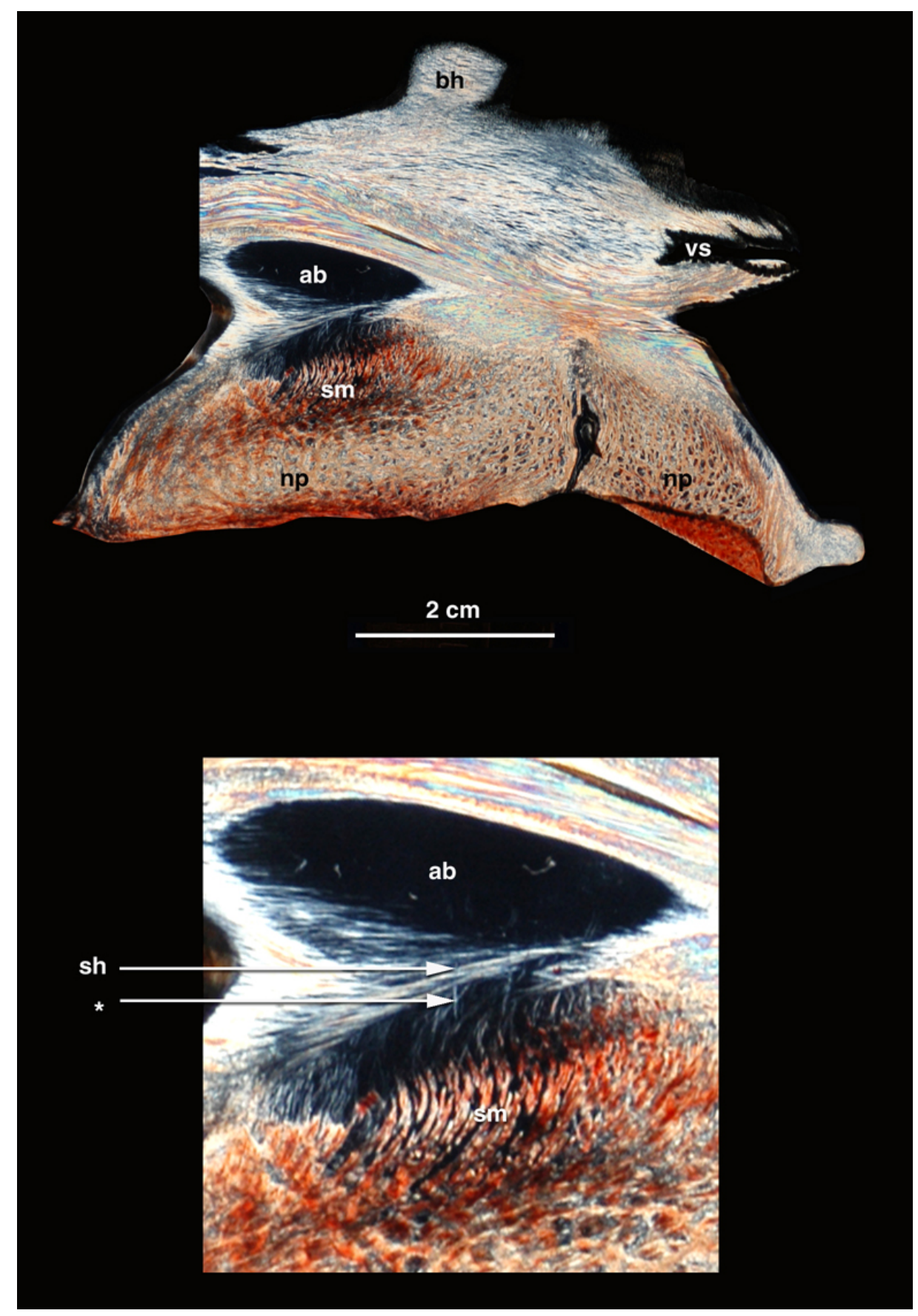

Fig. 26. Polarized light image of a transverse section through the Tursiops truncatus caudal melon, just at the boundary between the stem of the melon and the ventral surface of the cup of the melon. Rostral surface is facing the reader. ab, right anterior dorsal bursa; bh, lip of the blowhole; np, nasal plug; sh, bursal connective tissue sheath; sm, suspended nasal plug muscle; vs, vestibular sac; asterisk (*), tendons of the suspended nasal plug muscle. Inset: close up of the tendons of the suspended nasal plug muscle inserting into the bursal connective tissue sheath. The brightness and contrast of the inset was adjusted in Adobe Photoshop to highlight the tendons. 
The morphology of the suspended muscle changes along its length when viewed in the transverse body plane. Rostrally, the suspended muscle forms the ventral floor of the cone of the melon (Fig. 23). As the cone begins to decrease its cross-sectional area, the suspended muscle gradually occupies a more lateral position relative to the cone of the melon (Figs. 8, 15). Once the cone of the melon transitions into the right stem of the melon, the suspended muscle completely surrounds the stem’s circumference (Figs. 9, 27). Contraction of the suspended muscle may act to change the diameter of the right stem of the melon.

The suspended muscle is also intimately connected to the branch of the left caudal melon. When the left branch diverges from the cone of the melon, it branches laterally from the midline. In this region, the branch is filled with suspended muscle along its entire length (Fig. 7). The morphology of the suspended muscle and its spatial relationship to the left branch can be visualized best by sectioning the branch along the transverse body plane. At its rostral end (Fig. 8), the branch is completely filled with suspended muscle fibers. Further caudally (Fig. 9), just rostral to the left anterior dorsal bursa, the branch is occluded by embedded and suspended nasal

plug muscle. Thus, contraction of the suspended muscle may act to change the dimensions of the left branch. Both the embedded and suspended muscles of the nasal plug originate from the connective tissue matrix of the nasal plug and have highly organized tendon populations that connect with the cone, stem, cup, and branch of the caudal melon.

\section{DISCUSSION}

Echolocation signals are generated at the monkey lip dorsal bursae (MLDB) complex, in the form of tissue-borne vibrations, which are propagated along the length of the melon and transmitted into the surrounding water (Amundin, 1991, Cranford et al., 1996). In 1974, Norris 


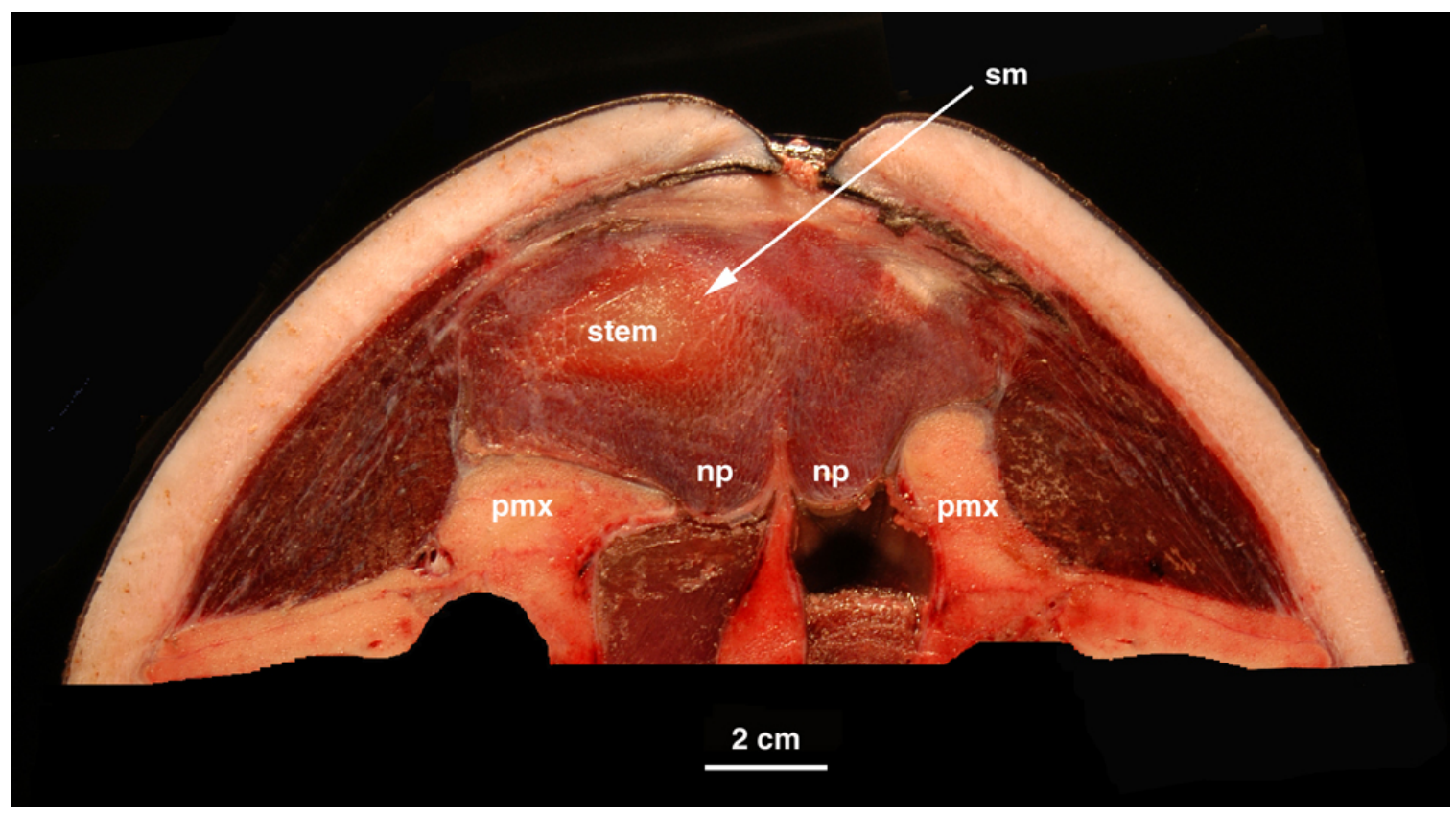

Fig. 27. Transverse section of the Tursiops truncatus forehead, approximately one centimeter rostral to the blowhole. Rostral surface is facing the reader. np, nasal plug; pmx, premaxillae; sfm, superficial facial muscle; sm, suspended nasal plug muscle. 
and Harvey proposed that the facial muscles and connective tissues in the forehead may act upon the melon to guide echolocation sounds to the surrounding water, but only three studies have investigated the gross morphology of these facial muscles (Lawrence and Schevill, 1956; Mead, 1975; Heyning, 1989). No study has investigated the orientations of the tendons of the facial muscles and their interactions with the melon. Thus, the functions of these muscles during the transmission of echolocation sounds have not been fully considered.

Polarized light imaging has permitted the regionally specific morphology of the melon to be described in detail, and has led to the identification and new descriptions of the cup, stem, cone, branch, and main body of the melon. This acoustic pathway, from the initial site of sound generation (the MLDB complex) to the rostral end of the melon, is acted upon by facial muscles. Polarized light imaging has revealed that the muscles have highly organized tendon populations that traverse the melon and insert into either the surrounding blubber, the connective tissue matrix of the nasal plug or the bursal connective tissue sheath. These connective tissues act as important "skeletal elements" for the facial muscles. The muscle fibers and their tendons lie at oblique angles relative to the transverse, longitudinal, and frontal body planes (Table 2, 3), suggesting that their actions could impose complex three-dimensional shape changes along the melon's length.

Thus, the muscles and tendons acting upon the melon may function to change the physical properties of the melon, which could change its acoustical properties. With detailed information on the origin, insertion, and tendon trajectories of these facial muscles, testable hypotheses can be generated for how these muscles may act upon the melon during the propagation of echolocation sounds. These hypotheses include: (1) the nasal plug muscle acts to modulate the frequency of oscillation of the MLDB complex; (2) the right caudal melon 
TABLE 2. The orientation and hypothesized action of each facial muscle that inserts into the right caudal melon and the main body of the melon.

\begin{tabular}{|c|c|c|c|}
\hline $\begin{array}{l}\text { Region of } \\
\text { the Melon }\end{array}$ & $\begin{array}{l}\text { Muscle/Tendons } \\
\text { inserting into Melon }\end{array}$ & $\begin{array}{l}\text { Plane of } \\
\text { Predominant } \\
\text { Fiber } \\
\text { Orientation }\end{array}$ & $\begin{array}{l}\text { Hypothesized } \\
\text { Action }\end{array}$ \\
\hline \multirow[t]{2}{*}{ Right Cup } & $\begin{array}{l}\text { Embedded muscle } \\
\text { (roof) }\end{array}$ & Frontal & $\begin{array}{l}\text { Change tension } \\
\text { in bursal sheath }\end{array}$ \\
\hline & Suspended muscle & Sagittal & $\begin{array}{l}\text { Change tension } \\
\text { in bursal sheath }\end{array}$ \\
\hline \multirow[t]{2}{*}{ Stem } & $\begin{array}{l}\text { Embedded muscle } \\
\text { (walls) }\end{array}$ & Frontal & $\begin{array}{l}\text { Change stem } \\
\text { length }\end{array}$ \\
\hline & Suspended muscle & $\begin{array}{l}\text { Sagittal and } \\
\text { Circumferential }\end{array}$ & $\begin{array}{l}\text { Change stem } \\
\text { diameter }\end{array}$ \\
\hline \multirow[t]{3}{*}{ Cone } & Suspended muscle & Sagittal & $\begin{array}{l}\text { Change cone } \\
\text { length }\end{array}$ \\
\hline & Pars anterointernus & Transverse & $\begin{array}{l}\text { Change cone } \\
\text { height }\end{array}$ \\
\hline & Oblique rostral muscle & Frontal & $\begin{array}{l}\text { Change cone } \\
\text { height and width }\end{array}$ \\
\hline \multirow[t]{3}{*}{ Main Body } & Lateral rostral muscle & Transverse & $\begin{array}{l}\text { Change main } \\
\text { body height }\end{array}$ \\
\hline & Medial rostral muscle & Transverse & $\begin{array}{l}\text { Change main } \\
\text { body height and } \\
\text { width }\end{array}$ \\
\hline & Oblique rostral muscle & Frontal & $\begin{array}{l}\text { Change main } \\
\text { body length }\end{array}$ \\
\hline
\end{tabular}


TABLE 3. The orientation and hypothesized action of each facial muscle that inserts into the left caudal melon.

\begin{tabular}{llll}
\hline $\begin{array}{l}\text { Region of } \\
\text { the Melon }\end{array}$ & $\begin{array}{l}\text { Muscle/Tendons } \\
\text { inserting into Melon }\end{array}$ & $\begin{array}{l}\text { Plane of } \\
\text { Predominant } \\
\text { Fiber } \\
\text { Orientation }\end{array}$ & $\begin{array}{l}\text { Hypothesized } \\
\text { Action }\end{array}$ \\
\hline Left Cup & $\begin{array}{l}\text { Embedded muscle } \\
\text { (wall) }\end{array}$ & Frontal & $\begin{array}{l}\text { Change tension } \\
\text { in bursal sheath } \\
\text { Embedded muscle } \\
\text { (floor) }\end{array}$ \\
Branch & Suspended muscle & Sagittal & $\begin{array}{l}\text { in bursal sheath } \\
\text { Change the }\end{array}$ \\
& Pars anterointernus & Transverse & $\begin{array}{l}\text { Change the } \\
\text { branch height }\end{array}$ \\
\hline
\end{tabular}


functions as a conical megaphone to concentrate and direct sound in the forward direction; (3) the rostral muscles act upon the main body of the melon to influence the direction of the echolocation beam.

The results from this study support the hypothesis that the nasal plug muscle acts as a frequency modulator. When pressurized air from the lower respiratory tract is passed over the MLDB complex, the dorsal bursae begin to vibrate (Cranford et al., 1996). The frequency at which a vibrating body will oscillate is related to its mass and stiffness (Gordon, 1978; Hartog, 1985). Assuming the mass of the right and left anterior dorsal bursae are constant, their frequency of oscillation will change with a change in their stiffness. The anatomical descriptions presented here demonstrate that the embedded and suspended nasal plug muscle have highly organized tendon populations that insert directly into the connective tissue sheath surrounding the right and left anterior dorsal bursae. Thus, contraction of the nasal plug muscle could increase the stiffness of the bursal connective tissue sheath and the adjacent nasal plug. By locally increasing the stiffness of the bursal connective tissue sheath, the frequency at which the right and left anterior dorsal bursae oscillate will also increase. Thus, the nasal plug muscle and its tendons may act as a frequency modulator that changes the vibrational frequency of the right and left MLDB complexes.

Within the field of acoustics, frequency is conventionally defined as the number of cycles or vibrations per second (Cutnell and Johnson, 2004). Cranford (pers. comm.) has suggested that the phrase "spectral properties" should be used instead of the term "frequency" when describing dolphin echolocation sounds, because frequency can also be used to describe the "repetition rate" of this event, i.e. the number of echolocation sounds that occur per unit time. Bottlenose dolphins (Tursiops truncatus) are capable of controlling both the spectral properties and the 
repetition rate of emitted echolocation clicks (Au, 1980; Au et al., 1988; Moore and Pawloski, 1990). The present study suggests that the nasal plug muscle may be able to affect the spectral properties and the repetition rate of the echolocation clicks by adjusting the stiffness of the bursal connective tissue sheath. Previous studies have demonstrated that the nasal plug muscle is active during the production of echolocation sounds. Ridgeway et al. (1980) used electromyographical (EMG) techniques to investigate the activity of selected facial and laryngeal muscles of bottlenose dolphins (Tursiops truncatus). These authors detected bilateral EMG activity in both muscles during echolocation sound production. The nasal plug and its associated musculature was further investigated by Amundin and Andersen (1983). These authors inserted EMG electrodes into the nasal plug muscle of phonating harbor porpoises (Phocoena phocoena) and also detected bilateral EMG activity during the production of the echolocation sounds. Amundin and Andersen (1983) concluded that echolocation sounds were not produced without EMG activity in the nasal plug muscle.

The present study also supports that hypothesis that the right caudal melon may function as a conical megaphone. The vibrational energy generated by the right anterior dorsal bursa is transmitted via the cup to the stem and cone of the melon. Sound enters through the narrow caudal end of the stem, is propagated through the stem and cone, until it reaches the large diameter base of the cone. Since the shape of the cone and stem is similar to a conical megaphone, they may act to concentrate and direct sound in the forward direction.

To develop this hypothesis further, the average height and width of the stem and cone were measured from the transverse serial sections taken through the whole frozen dolphin head (Figs. 13, 14, 15, 27). These measurements demonstrate that the stem of the melon (sections 13) is shaped as a cylinder with a diameter between $1-1.3 \mathrm{~cm}$ (Fig. 28). The cone of the melon 


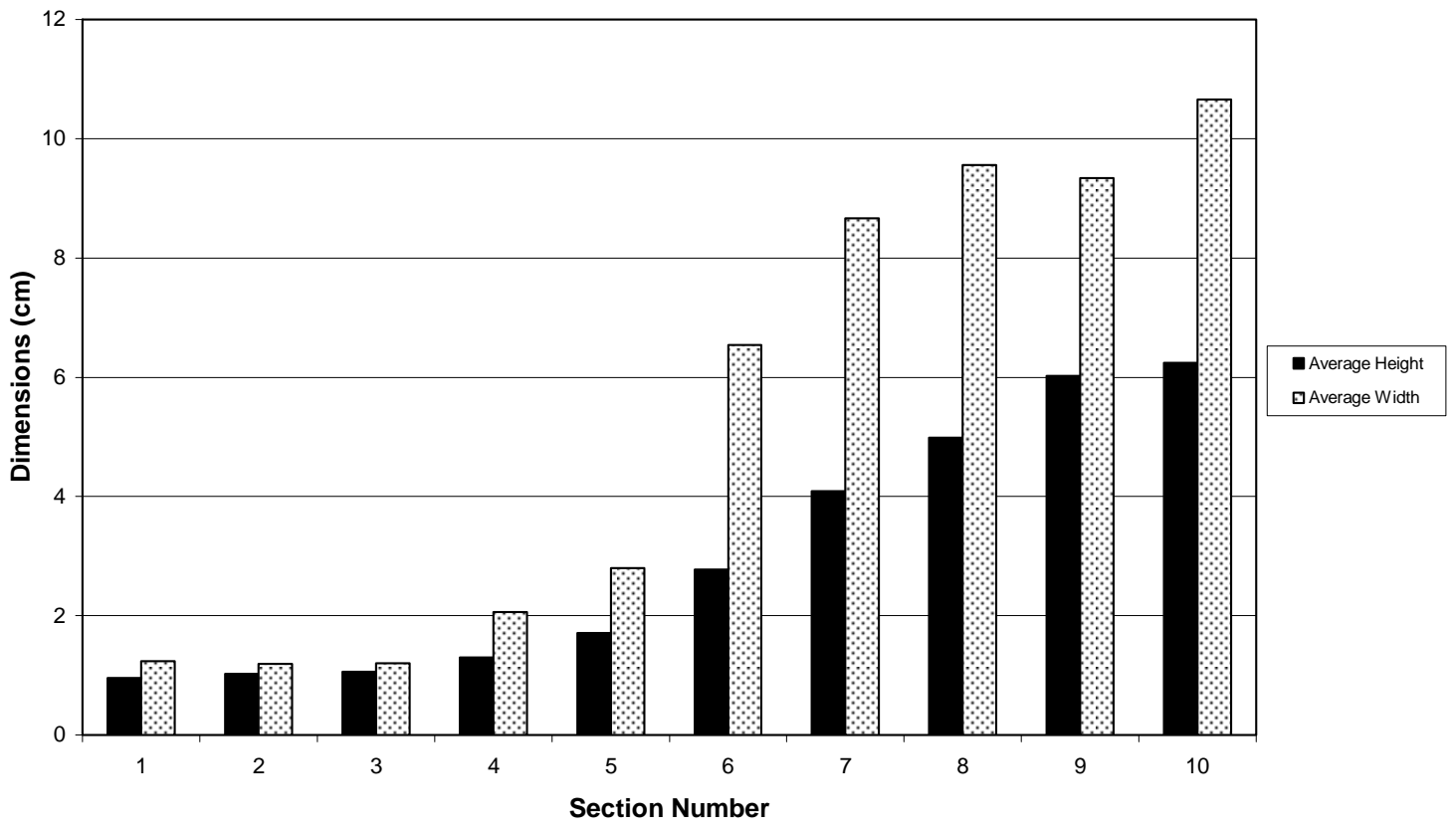

Fig. 28. Average height and width of the stem and cone of the right caudal melon in a bottlenose dolphin, Tursiops truncatus. Sections 1-3 represent the stem and sections 4-10 represent the cone. 
(sections 4-10) is conical in shape as its height and width gradually increase along its entire length. These quantitative measurements demonstrate that it is appropriate to model the stem and cone of the melon as a megaphone. If the diameter of a megaphone changes, relative to the wavelength of sound being transmitted through it, the width of the emitted sound beam will change (Watson, 1935). The dimensions of the megaphone are compared to the wavelength of sound being transmitted though it, then the width of the emitted sound beam will change (Watson, 1935). In bottlenose dolphins (Tursiops truncatus), the wavelength of an emitted echolocation signal can be calculated by dividing the speed of sound through seawater (1545.6 meters per second at $30^{\circ} \mathrm{C}$, as reported by Denny, 1993) by the peak frequency of the echolocation signal (120 kHz, as reported by Au, 1993) (Cutnell and Johnson, 2004). Thus, the estimated wavelength for an emitted echolocation signal is approximately $1.3 \mathrm{~cm}$. If the diameter of the megaphone is less than the wavelength of the emitted sound $(1.3 \mathrm{~cm})$, then the beam tends to spread out as it exits the megaphone. In contrast, if the diameter of the megaphone is greater than the sound's wavelength $(1.3 \mathrm{~cm})$, the emitted sound will narrow and propagate along the central axis of the megaphone. The quantitative measurements discussed above suggest that the dimensions of the stem are approximately equal to the wavelength of the emitted sound. Thus, the sound will propagate through the stem with minimal energy loss in the forward direction (Kock, 1965). Since the height and width of the cone are greater than the wavelength, these measurements suggest that the cone may function to narrow the emitted echolocation beam.

This study demonstrates that there are facial muscles that act upon the stem and cone of the melon, suggesting that the shape of these regions may be able to be actively controlled. The facial muscles inserting into the stem of the melon completely surround the circumference of this 
tube of fat, suggesting that muscle contraction could act to decrease its diameter. The muscles and tendons acting upon the cone of the melon lie within the sagittal and frontal body planes, and could act to change the length and height of the cone. Thus, these muscles may function, by changing the diameter of the melon "megaphone," to change the width of emitted echolocation beam.

The echolocation beam of the bottlenose dolphin is a relatively narrow beam of sound (Norris, 1964; Evans et al., 1964; Norris and Evans, 1967; Au et al., 1978; Au et al., 1986; Au, 1993) and its width determines the amount of spatial resolution it can provide to the echolocating dolphin. Thus, it would appear to be beneficial for dolphins to emit a narrow echolocation beam because it will increase spatial resolution and decrease the amount of received noise (Au, 1978).

Using density values from CT scans, Cranford et al. (1996) also demonstrated that the caudal melon and the surrounding “connective tissue theca” are shaped like a megaphone, although these authors compared these features to the bell of a trumpet. The results of this study suggest that the "connective tissue theca” is not a single, discrete structure. Instead, the polarized light images reveal that the caudal melon is surrounded caudally and ventrally by the nasal plug and nasal plug muscle, laterally by the oblique rostral muscles tendons and dorsally by the pars anterointernus tendons (Figs. 5, 6, 15, 16). Thus, the "connective tissue theca" of Cranford et al. (1996) is formed by the muscle, tendons, and connective tissues surrounding the caudal melon.

Lastly, the present study supports the hypothesis that the rostral muscles may act upon the main body of the melon to influence the direction of the echolocation beam. The results of this study suggest two possible mechanisms for this hypothesized function. First, contraction of the rostral muscles may be able to increase the stiffness of the blubber surrounding the main 
body of the melon, which may act to refract the emitted echolocation signals. When sound is propagated through a homogeneous medium, it takes a linear path (Watson, 1935; Au, 1993). But if sound is passed through media with different physical properties, sound will be reflected and refracted at the boundaries between the media (Watson, 1935; Haliday and Resnick, 1970; $\mathrm{Au}, 1993)$. Sound exiting the dolphin forehead must pass from the melon, to the surrounding blubber, and then into the surrounding water. Along this pathway, sound will be reflected and refracted at each of these boundaries. Previous research has focused on how the acoustic fats within melon function to refract sound within the melon (e.g. Litchfield et al., 1971; Varanasi and Malins, 1972; Litchfield et al., 1975; Malins and Varanasi, 1975; Varanasi et al., 1982), but the present study is the first to suggest that the facial muscles and connective tissues in the forehead may actively adjust the refraction of the beam.

The amount of refraction that occurs across two media depends upon the differences in both the density and Young's modulus of elasticity (i.e stiffness) (Watson, 1935). Soldevilla et al. (2005) measured the stiffness of the acoustic fat of the melon and the surrounding blubber in a neonate Cuvier's beaked whale (Ziphius cavirostris). These authors found that blubber has a higher Young's modulus than the melon. Because the rostral muscles insert into the blubber surrounding the melon, contraction of the rostral muscles may increase the local stiffness of the blubber, which could act to change the refraction of the emitted echolocation beam.

Second, the rostral muscles may act to change the shape of the main body of the melon, which may also influence the direction of the echolocation beam. Rostral muscle contraction may change the radii of curvature of the main body of the melon and act to bend the emitted echolocation beam. Thus, the main body of the melon may function as a dynamic lens to subtly adjust the direction of the echolocation beam as it exits the forehead. To date, no study has 
investigated the EMG activity of the rostral muscles during the production of the echolocation sounds. This imformation could determine whether the rostral muscles contract unilaterally, bilaterally, or differentially during echolocation. The morphology described here combined with the EMGs may illuminate how the rostral muscles subtly adjust the direction of the echolocation beam as it travels through the melon and into the surrounding water.

The morphology presented in this study supports the hypothesis set forth by Norris and Harvey (1974), suggesting that the muscles in the dolphin head may actively work on the melon during echolocation. To develop this hypothesis further and to enhance our understanding of how these muscles function during echolocation, the tendinous connections between the facial muscles, melon, and connective tissue in the forehead were visualized with polarized light imaging techniques. This study is the first to determine that the melon rests in a basin of muscle and within that basin, the muscle fibers and the tendons lie at oblique angles relative to the transverse, frontal, and sagittal body planes. The morphology of the facial muscles and their tendons further suggests that the sound propagation pathway in bottlenose dolphins (Tursiops truncatus) is a highly tunable system. The facial muscles and their tendons may affect the frequency, width, and directionality of the emitted echolocation beam, by changing the shape and/or stiffness of the melon. Although acoustic fat plays a crucial role in the transmission of sound during echolocation, those specialized fatty structures within the dolphin head are actively worked upon by highly organized facial muscles and connective tissues. 


\section{LITERATURE CITED}

Amundin M. 1991. Helium effects on the click frequency spectrum of the harbor porpoise, Phocoena phocoena. Journal of the Acoustical Society of America 90: 53-59

Amundin M, Andersen SH. 1983. Bony nares air pressure and nasal plug activity during click production in the harbour porpoise, Phocoena phocoena, and the bottlenose dolphin, Tursiops truncatus. Journal of Experimental Biology 105: 275-282.

Au WL, Floyd RW, Haun JE. 1978. Propagation of Atlantic bottlenose dolphin echolocation signals. Journal of the Acoustical Society of America 64: 411-422.

Au WWL. 1980. Echolocation signals of the Atlantic bottlenose dolphin (Tursiops truncatus) in open waters. In: Busnel R, Fish JF. Animal Sonar Systems. New York, Plenum Press, p. 251282.

Au WWL, Moore PWB, Pawloski D. 1986. Echolocation transmitting beam of the Atlantic bottlenose dolphin. Journal of the Acoustical Society of America 80: 688-691.

Au WWL, Penner RH, Turl CW. 1988. Propagation of beluga echolocation signals. In: Nachtigall PE, Moore PWB, editors. Animal Sonar: Processes and Performance. New York: Plenum Press. p. 47-51.

Au WWL. 1993. The sonar of dolphins. New York: Springer-Verlag. 277 p.

Cranford TW, Amundin M, Norris KS. 1996. Functional morphology and homology in the odontocete nasal complex: Implications for sound generation. Journal of Morphology 228: 223285.

Cutnell JD, Johnson KW. 2004. Physics, sixth edition. New York: John Wiley \& Sons, Inc. $992 \mathrm{p}$.

Denny MW. 1993. Air and water: The biology and physics of life's media. Princeton, NJ: Princeton University Press. 341 p.

Evans WE, Sutherland WW, Beil RG. 1964. The directional characteristics of Delphinid sounds. In: Tavolga WN, editor. Marine Bio-Acoustics. New York, Pergamon Press, p. 353372.

Geraci JR, Lounsbury VJ. 2005. Marine mammals ashore: A field guide for strandings. Baltimore, MD: National Aquarium in Baltimore, Inc. 371 p.

Gordon JE. 1978. Structure or why things don’t fall down. London: Da Carpo Press. 395 p.

Halliday D, Resnick R. 1970. Fundamentals of physics. New York: John Wiley \& Sons. 554 p. 
Hamilton JL, Dillaman RM, Mclellan WA, Pabst DA. 2004. Structural fiber reinforcement of keel blubber in harbor porpoise (Phocoena phocoena). Journal of Morphology 261: 105-117.

Hartog JP. 1985. Mechanical vibrations. New York: Dover Publications, Inc. 436 p.

Heyning JE. 1989. Comparative facial anatomy of beaked whales (Ziphidae) and a systematic revision among the families of extant odontocete. Contributions in Science 405: 1-64.

Heyning JE, Mead JG. 1990. Evolution of the nasal anatomy of cetaceans. In: Thomas J, Kastelein R, editors. Sensory Abilities of Cetaceans: Laboratory and Field Evidence. New York: Plenum Press. p. 67-79.

Howell AB. 1930. Aquatic Mammals. Springfield, IL: Charles C. Thomas. 338 p.

Kock, WE. 1965. Sound waves and light waves. Garden City, NY: Anchor Books. 165 p.

Lawrence B, Schevill WE. 1956. The functional anatomy of the delphinid nose. Bulletin of the Museum of Comparative Zoology 114: 103-182.

McKenna MF. 2005. Comparative morphology of the odontocete melon: Functional and evolutionary interpretations. MSc Thesis: San Diego State University.

Mead J. 1975. Anatomy of the external nasal passages and facial complex in the Delphinidae (Mammalia: Cetacea). Smithsonian Contributions to Zoology 207: 1-72.

Miller GS. 1923. The telescoping of the cetacean skull. Smithsonian Miscellaneous Collection 76: $1-55$.

Moore PWB, Pawloski DA. 1990. Investigations on the control of echolocation pulses in the dolphin (Tursiops truncatus). In: Thomas J, Kastelein R, editors. Sensory Abilities of Cetaceans: Laboratory and Field Evidence. New York: Plenum Press. p. 305-316.

Norris KS, Prescott JH, Asa-Dorian PV, Perkins, P. 1961. An experimental demonstration of echolocation behavior in the porpoise, Tursiop truncatus (Montagu). Biological Bulletin 120: 163-176.

Norris, KS. 1964. Some problems of echolocation in cetaceans. In: Tavolga, WN, editor. Marine Bio-Acoustics. New York, Pergamon Press, p. 317-336.

Norris KS, Evans WE. 1967. Directionality of echolocation clicks in the rough-tooth porpoise, Steno bredanesis (Lesson). In: Tavolga WN, editor. Marine Bio-Acoustics. New York, Pergamon Press, 305-316.

Norris KS. 1969. The echolocation of marine mammals. In: Andersen HT, editor. The Biology of Marine Mammals. New York, Academic Press, 391-423. 
Norris KS, Harvey GW. 1974. Sound transmission in the porpoise head. Journal of the Acoustic Society of America 56: 659-664.

Pouchet MG, Beauregard H. 1885. Sur “l’organe des spermaceti.” Comptes Rendus de Societe Biologique 11: 343-344.

Presnell JK, Schreibman MP. Humason's Animal Tissue Techniques, fifth edition. Baltimore, MD: The John Hopkins University Press. 572 p.

Ridgway SH, Carder DA, Green RF, Gaunt AS, Gaunt SLL, Evans WE. 1980.

Electromyographic and pressure events in the nasolaryngeal system of dolphins during sound production. In: Busnel R, Fish JF. Animal Sonar Systems. New York, Plenum Press, p. 239249.

Rommel S. 1990. Osteology of the bottlenose dolphin. In: Leatherwood S, Reeves RR, editors. The Bottlenose Dolphin. San Diego: Academic Press. p 51-68.

Rommel, SA, Costidis AM, Fernandez A, Jepson PD, Pabst DA, McLellan WA, Houser DS, Cranford TW, van Helden AL, Allen DM, Barros NB. 2006. Elements of beaked whale anatomy and diving physiology and some hypothetical causes of sonar-related stranding. Journal of Cetacean Research and Management 7: 198-209.

Soldevilla MS, McKenna MF, Wiggins SM, Shadwick RE, Cranford TW, Hildebrand JA. 2005. Cuvier's beaked whale (Ziphius cavirostris) head tissues: physical properties and CT imaging. Journal of Experimental Biology 208: 2319-2332.

Varanasi U, Markey D, Malins DC. 1982. Role of isovaleroyl lipids in channeling of sound in the porpoise melon. Chemistry and Physics of Lipids 31: 237-244.

Wainwright SA, Biggs WD, Currey JD, Gosline JM. 1976. Mechanical design in organisms. Princeton, NJ: Princeton University Press. 423 p.

Watson FR. 1935. Sound: An elementary textbook on the science of sound and the phenomena of hearing. London: John Wiley \& Sons. 219 p. 